Illinois State University

ISU ReD: Research and eData

Theses and Dissertations

$6-2-2015$

\title{
'Cancer is Like Teenagers': Figurative Comparisons in Surgical Consultations for Early-Stage Breast Cancer
}

Keith Cox

Illinois State University, keith.cox@hotmail.com

Follow this and additional works at: https://ir.library.illinoisstate.edu/etd

Part of the Sociology Commons

\section{Recommended Citation}

Cox, Keith, "'Cancer is Like Teenagers': Figurative Comparisons in Surgical Consultations for Early-Stage Breast Cancer" (2015). Theses and Dissertations. 428.

https://ir.library.illinoisstate.edu/etd/428

This Thesis is brought to you for free and open access by ISU ReD: Research and eData. It has been accepted for inclusion in Theses and Dissertations by an authorized administrator of ISU ReD: Research and eData. For more information, please contact ISUReD@ilstu.edu. 


\title{
'CANCER IS LIKE TEENAGERS': FIGURATIVE COMPARISONS IN SURGICAL CONSULTATIONS FOR EARLY-STAGE BREAST CANCER
}

\author{
Keith Cox
}

60 Pages

August 2015

This thesis reports findings from a conversation analytic study that investigate how surgeons describe cancer to early-stage breast cancer patients during preoperative consultations. Drawing upon audio recordings of actual consultations, this study examines one surgeon's use of a type of figurative expression, an analogy, to describe what cancer is and how it behaves. My analysis focuses on the role that this analogy plays in the activities that unfold in one phase of the surgical consultation, and reveals some social organizational dimensions of figurative expressions that have gone unexplored in prior research. 
'CANCER IS LIKE TEENAGERS': FIGURATIVE COMPARISONS IN SURGICAL CONSULTATIONS FOR EARLY-STAGE BREAST CANCER

\title{
KEITH COX
}

\author{
A Thesis Submitted in Partial \\ Fulfillment of the Requirements \\ for the Degree of \\ MASTER OF SCIENCE \\ Department of Sociology and Anthropology \\ ILLINOIS STATE UNIVERSITY
}


(C) 2015 Keith Cox 
'CANCER IS LIKE TEENAGERS': FIGURATIVE COMPARISONS IN SURGICAL CONSULTATIONS FOR EARLY-STAGE BREAST CANCER

KEITH COX

COMMITTEE MEMBERS:

Virginia Teas Gill, Chair

Diane Bjorklund

Christopher Wellin 


\section{ACKNOWLEDGMENTS}

This thesis would not have been possible without the guidance and support I received along the way from my friends and family, and, of course, my stellar thesis committee. I would like to thank my committee members, Dr. Diane Bjorklund and Dr. Christopher Wellin, for their suggestions throughout the research process. As seasoned academics, you brought a wealth of intellect and style that flavored my thinking and writing in ways that I'll never be able to identify, but will forever be grateful. I would like to give special thanks to my mentor and friend, my thesis chair, Dr. Virginia Teas Gill. You taught me how to learn, and made me want to teach — you changed my life. I'll never be able to pay you back for all that you have done for me, but I'll make it a point to pay it forward. So help me Hannah.

K.C. 


\section{CONTENTS}

ACKNOWLEDGMENTS $\quad$ i

$\begin{array}{ll}\text { CONTENTS } & \text { ii }\end{array}$

CHAPTER

I. INTRODUCTION 1

II. LITERATURE REVIEW 3

Linguistics and Figurative Expressions 3

Figurative Expressions and Social Meanings $\quad 5$

Figurative Language in Clinical Encounters $\quad 6$

Gaps in the Literature $\quad 8$

A Conversation Analytic Approach to Figurative Expressions 12

$\begin{array}{ll}\text { III. DATA AND METHOD } & 15\end{array}$

$\begin{array}{ll}\text { IV. } & 18\end{array}$

Structure of the Surgical Consultation 18

The Focal Phenomenon and Its Interactional Environment 18

$\begin{array}{ll}\text { Case } 1 & 20\end{array}$

Case $2 \quad 31$

Case $3 \quad 37$

Case $4 \quad 44$

$\begin{array}{ll}\text { V. DISCUSSION } & 50\end{array}$

Conclusions and Implications $\quad 50$

Limitations $\quad 53$

$\begin{array}{ll}\text { REFERENCES } & 54\end{array}$

APPENDIX A: TRANSCRIPTION NOTATION 59

$\begin{array}{ll}\text { ENDNOTES } & 60\end{array}$ 


\section{CHAPTER I}

\section{INTRODUCTION}

Breast cancer is the second most commonly-diagnosed cancer in women, with an estimated 289,780 diagnoses expected in 2015 alone (ACS 2015). Modern technologies make it easier to detect breast cancer at an early stage, and today's treatment options are more sophisticated and diverse than ever (ACS 2015). However, not all breast cancers can be treated the same. Patients' treatments must be tailored to the particular biological configurations of their cancer. Consequently, today's patients need to know the specific characteristics of their cancer to understand what kind of treatment is offered or recommended and why, and how it might affect their day-to-day wellbeing, not only for the duration of treatment, but for the rest of their lives.

Notwithstanding the diversity of treatment options for breast cancer, most patients' care will begin with some form of surgery to excise the affected area(s) (CCC 2014). After receiving a diagnosis of breast cancer, patients will typically meet with a surgeon for a preoperative consultation to discuss surgical options. But how exactly do surgeons describe cancer during these consultations, and how do they educate or inform patients about their specific type of cancer? A review of a corpus of audiotapes of such encounters revealed a striking feature: one surgeon regularly used a type of figurative expression, an analogy, to describe what cancer is and how it behaves. For example: 
Dr: "I like to consider cancer teenagers: They're not obeying the rules, they do not stay where they're supposed to, and they do not come home when they're supposed to."

This study investigates some of the social organizational dimensions of this analogy, and the role it plays in the activities that unfold in one phase of the surgical consultation. I explore how social actions like surgeons' informings and patients' news receipts are produced sequentially, and operate reflexively, to achieve observable social activities such as educating and being educated. My primary research questions are: (1) How do surgeons educate early-stage breast cancer patients about cancer in general and/or their cancer, specifically? (2) How do patients display their understandings of the information that surgeons provide related to cancer in general and/or patients' cancer, specifically? And (3) do participants encounter any interactional dilemmas in the phase of the visit where descriptions of cancer take place? If so, how do participants orient to (and deal with) such interactional dilemmas?

The remainder of this report will unfold as follows: First I review the various literatures dealing with speakers' use of figurative language, paying special attention to how researchers have analyzed analogy, metaphor, and other forms of imagery used to describe illness. Next, I highlight some neglected social dimensions of figurative expressions in talk-in-interaction. Then I introduce the current study and discuss its relevance for research in this domain, and I present findings about the focal phenomenon. Finally, I discuss the implications that these findings have for future research on the nature and function of figurative comparisons in real-time social interaction in medical contexts. 


\section{CHAPTER II}

\section{LITERATURE REVIEW}

\section{Linguistics and Figurative Expressions}

Cognitive linguists have studied metaphor and analogy, two types of figurative comparison (Lakoff and Johnson 1980). Metaphor and analogy both facilitate understanding via comparison; they invite people to draw upon existing stocks of knowledge to make sense of complex concepts. Metaphors generally consist of nonliteral, broad strokes comparisons between two seemingly unrelated conceptual categories (i.e., "A is B"). Analogies, on the other hand, generally consist of literal comparisons that emphasize a specific set of shared attributes (i.e., A is like B in terms of $\mathrm{X}, \mathrm{Y}$, and Z). To some degree, then, analogy can be seen as an explicit form of metaphor, metaphor can be seen as an implicit form of analogy, and both can be seen as forms of figurative comparison.

The ostensible link between figurative comparisons and meaning (and variations therein) has motivated researchers to delve deeper into their nature and function at the level of cognition. Lakoff and Johnson's (1980) cognitive linguistic approach to the study of metaphor, Conceptual Metaphor Theory (CMT), is one of the most influential perspectives to date. As linguists, Lakoff and Johnson (1980) are chiefly concerned with language; however, CMT is recognized for its capacity to reconcile conceptions of language and cognition within a single analytical framework. A central tenet of CMT is 
that metaphor operates at the level of cognition: It "is principally a way of conceiving of one thing in terms of another, and its primary function is understanding" (Lakoff and Johnson 1980:36). Metaphor embodies an automatic cognitive linkage between two conceptual domains — the "source" and the "target" — such that one thing (the target) is conceived of in terms of another (the source) so as to facilitate understanding of the target (Lakoff and Johnson 1980).

The primacy of cognition in CMT reflects the broader notion that a speaker's use of metaphor in talk is interesting insofar as the metaphor stands on behalf of an underlying cognitive process. Lakoff and Johnson (1980:3) argue that language springs from, and reflects, "the same conceptual system that we use in thinking and acting" and therefore it "is an important source of evidence for what that system is like." Significantly however, Lakoff and Johnson (1980) are not interested in what people say, per se; for them what people say is only the surface-level manifestation of a far deeper and more interesting cognitive process.

Scholars of rhetoric have also recognized that figurative comparisons are neither random nor insignificant. In fact, rhetoriticians see them as powerful persuasive devices that are particularly well-suited for the advancement of "argument by definition" (Zarefsky 1998, as cited in Schiappa 2003:130). Instead of "explicitly advancing an argument about a definition (X should be defined as $\mathrm{Y}$ ) or constructing an argument from definition (All $\mathrm{X}$ are $\mathrm{Z}$; $\mathrm{Y}$ is an $\mathrm{X}$; therefore $\mathrm{Y}$ is $\mathrm{Z}$ ), advocates simply posit that $\mathrm{X}$ is $\mathrm{Y}$ and move on" (Schiappa 2003:130). In other words, these devices can have a social function - people can use them to get things done. 


\section{Figurative Expressions and Social Meanings}

Researchers from the Symbolic Interactionist (hereafter, SI) tradition argue that the ways in which people talk about illness have important social antecedents and social consequences. When people use metaphor, analogy, and other types of figurative expressions to describe illness, it frames the way they think about illness, affects how they treat their bodies, and how their bodies are treated by others. Illness is not just biological, it has social dimensions as well; however, social constructionists argue that the latter are not necessarily bound to the former: What a disease is on a biological level does not directly constitute what it means in the social world (Eisenberg 1977; Freidson 1970; cf. Conrad and Barker 2010). Social constructionism is a conceptual framework that incorporates features of SI (Blumer 1969) and phenomenology (Schutz 1967) to foreground the interplay of shared meanings and lived experiences (see Conrad and Barker 2010, for a detailed overview). Social constructionists believe that the reality of a given medical condition has just as much, or more, to do with the sociocultural meanings attached to it as it does with the physiopathology that characterizes it. Some of the early work on the social construction of illness focused on the relationship between patients' illness experiences and their presentation of "self," and how both are constructed and maintained in and through social interaction (Charmaz 1991; Glaser and Strauss 1965; cf. Conrad and Barker 2010).

Sontag (1978) was among the first scholars to scrutinize the widespread use of martial metaphors (such as, "Cancer is War") in talk concerning illness, especially tuberculosis and cancer. She argued that metaphors imbue illnesses with symbolic meanings, and that these symbolic meanings can have negative social ramifications. 
People internalize the meanings ascribed to illnesses in their culture and come to understand illnesses in particular, culturally-defined ways as a result. Consequently, when people in the United States use metaphors to liken cancer to war, the patient becomes a "soldier" and his or her body, a "battleground" (Sontag 1978; Fuks 2010). The implication is that people come to see their own health as a proxy for personal success or failure, an orientation that reflects a larger cultural preoccupation with individual success in the U.S. When people understand illness in this way they come to see health outcomes as a reflection of personal effort, will, and merit (Sontag 1978). Thus for Sontag (1978), among others, it is not necessarily the use of metaphor per se that is at issue: there is nothing intrinsically problematic about this particular linguistic device. Rather, she critiques the specific symbolic meanings that martial metaphors convey, and how these symbolic meanings come to bear on the illness experience.

Others have argued that, because of these meanings, health-related metaphors can play a positive role in shaping public perceptions of conditions and in spurring behavioral changes. For example, Barry et al.'s (2009) study of obesity metaphors and public policy support showed that the use of negative metaphors to describe obesity (e.g., "Obesity is Sinful") may shape perceptions of the disease, leading to increased public support for various policies designed to curtail it.

\section{Figurative Language in Clinical Encounters}

Over the past several decades, scholars from several disciplines have investigated the use of figurative expressions in clinical contexts. Some have argued that they can be put to practical use in clinical encounters. Reisfield and Wilson (2004), who are both physicians, express a stance on metaphor use in clinical settings that has become quite 
common among health care professionals in recent years, that these devices can be important tools for creating shared understanding (Niebert, Marsch, and Treagust 2012):

For the physician, metaphors can be time-efficient tools for helping patients understand complex biologic processes. For patients, metaphors can impose order on a suddenly disordered world, helping them to understand, communicate, and thus symbolically control their illness. And for the therapeutic relationship, the language of metaphor can serve as the basis for the shared understanding of clinical reality. (Reisfield and Wilson 2004:4024)

Some evidence suggests that doctors' use of figurative comparisons may enhance patients' perceptions of their doctors' communicative competence. For example, Casarett et al., (2010) investigated the relationship between doctors' use of metaphors and analogies in difficult conversations and patients' ratings of doctors' communication skills. The researchers used audio recordings of medical consultations and post-consultation patient surveys as data. They found that patients' ratings of doctors' communication skills were positively associated with the number of metaphors and analogies doctors used when talking with patients. There is also evidence that figurative descriptions of illness can promote patient participation in illness prevention measures. Scherer, Scherer, and Fagerlin (2015) conducted three experiments designed to measure the association between written metaphoric descriptions of influenza and participants' intentions to get vaccinated. They found that participants who were ambivalent about getting the influenza vaccination prior to the study were significantly more likely to say that they planned to get a flu shot when they read a metaphoric description of the virus than were those who read a strictly biomedical description.

Other studies have found that various types of figurative expressions have different impacts on patients' perceptions of the information they receive about illness. Whaley et al. (2014) conducted an experiment to investigate: (1) whether or not people 
respond differently to analogy-based explanations of diabetes than they do to strictly biological explanations of the disease; and (2) whether or not the type of analogy used to explain diabetes makes a difference in how people respond to it. Participants in the control group received a biomedical description of diabetes while participants in each of the two experimental groups received separate analogy-based descriptions of the disease. Participants who received either of the two analogy-based descriptions of diabetes were more likely to rate the explanation they received as "effective" and "trustworthy" than were those in the control group who received a standard biomedical description. However, participants who read a description of diabetes that likened it to "streets" (blood vessels) full of "cars" (glucose) that do not have enough "driveways" (insulin) to get the cars into "garages" (cells) were more likely to report a positive attitude towards the disease than were those who read an analogical description that likened glucose to a "key that unlocks" sugar in cells (Whaley et al., 2014:74).

In these studies, researchers investigated some of the practical dimensions of figurative expressions used to describe illness. Analysts in this area are interested in how figurative expressions shape patients' attitudes, beliefs, behaviors, and perceptions about care in illness contexts.

\section{Gaps in the Literature}

As noted, scholars in the SI tradition are primarily interested in how metaphor, analogy, and other forms of imagery mirror cultural values and beliefs, and how these come to bear on patients' illness experience. Accordingly, they seek to understand the symbolic meanings associated with illness as evidenced in patients' narratives about doctor-patient encounters during in-depth interviews (e.g., Glaser and Strauss 1965; 
Charmaz 1991). This type of research illuminates patients' perspectives and sociocultural meanings, but interview methods only provide secondhand accounts of what occurred during medical consultations. Consequently, they cannot show how people put figurative expressions to use in the clinic. This is also the case for the experimental methods used by clinical researchers (e.g., Whaley et al., 2014; Scherer, Scherer, and Fagerlin 2015). These methods reveal some of the implications associated with using various metaphors and analogies to describe illness in written form, but they neglect the ways in which people actually use these figurative comparisons in talk-in-interaction.

Likewise, for many years CMT scholars did not look at how people actually use metaphors in naturally-occurring talk; they formulated their own metaphors based on commonsense understandings of how people usually talk about specific concepts. By examining idiomatic phrases like "Things are looking up" and "Things are at an all-time low" for example, Lakoff and Johnson (1980:16) made the case for a general cognitive orientation to the conceptual metaphor "Good is Up," and its converse, "Down is Bad." More recently, CMT scholars (and variants thereof) began to use naturally-occurring talk as data (Cameron 1999, 2008; Cameron and Deignan 2003; Semino, Heywood, and Short 2004; etc.). However, much of the CMT-inspired research in this vein focuses on the frequency and distribution of individual metaphoric utterances in talk (e.g., Cameron and Stelma 2004) rather than analyzing them in the context of the ongoing stream of activities in conversation. Some researchers in this area continue to apply a more traditional CMT perspective to naturally-occurring talk by extrapolating conceptual metaphors from indexical linguistic expressions (e.g., Skelton, Wearn, and Hobbs 2002). Here, as before, studies generally involve combing through transcriptions of actual conversations, either 
manually or with the aid of software programs, for utterances that imply some orientation to particular conceptual linkages. Researchers then extract these utterances from their interactional contexts and attempt to map the utterances' approximate trajectories in an effort to reveal the overarching conceptual framework — the specific "A is B" — within which participants make sense of a given concept. For instance, a word like fight, when used in discourse on cancer, might be interpreted as evidence for a speaker's use (conscious or not) of the conceptual metaphor "Cancer is War" to make sense of the disease. $^{1}$

The questions that researchers ask and the methodological tools they employ inevitably make some social dimensions of illness more salient, while concealing others. As a result, many of the social organizational dimensions surrounding metaphor and analogy in talk about illness have gone unexplored. Prior studies on metaphor and analogy have been based on invented examples (e.g., Lakoff and Johnson 1980), on participants' recollections of what occurred, (e.g., Harrow et al., 2008), or utterances stripped of context (e.g., Skelton, Wearn, and Hobbs 2002). In each instance, the type of data and methods researchers use directly reflected, and allowed access to, their particular scholarly interests. However, they conceal the role figurative expressions may play in achieving activities during actual talk-in-interaction, and the ways in which participants draw upon context as an interactional resource to understand what a figurative expression may be doing in a particular location in the stream of talk. Conversation analysis (CA) provides a way to access these aspects of the social organization of figurative expressions. CA was created in the 1960's by Harvey Sacks ([1992] 1995) in collaboration with Emanuel Schegloff and Gail Jefferson (Sacks, Schegloff, and Jefferson 
1974). At the time sociology was dominated by Structural Functionalism (Parsons 1951), a theoretical perspective that, for Sacks, failed to describe social order in empiricallyverifiable ways. This was a substantial issue for Sacks because he, "figured that sociology could not be an actual science unless it was able to handle the details of actual events, handle them formally, and in the first instance be informative about them in the direct ways in which primitive sciences tend to be informative - that is, that anyone else can go and see whether what was said is so" (Sacks 1984:26). Eventually Sacks realized he could study naturally-occurring talk with the aid of audio recordings. Assisted by a transcription notation system designed by Gail Jefferson (1974; see Appendix A), the nuanced features of talk — the sequencing of turns, the pitch, volume, and inflection of utterances, etc. — could be captured. Soon it was clear, and empirically demonstrable, that people use talk methodically, in highly complex and orderly ways. That is, people use talk to build recognizable actions and activities, as well as social identities and institutions, i.e., to accomplish social facts (see Heritage and Clayman 2010).

This development was groundbreaking in many ways, perhaps most notably in that it could capture how members of society create recognizable social order in actual occasions of real-time social interaction. In this way CA embodies Garfinkel's (1964) ethnomethodological perspective, which stands in opposition to Parsons's (1951) rolebased explanation of social order. From an ethnomethodological perspective people are not merely rule-governed "judgmental dopes" (Garfinkel 1967:68). When a person's action is looked at in terms of how (vs. why) it was accomplished it becomes clear that the person was doing a lot of work in the moment to make the action recognizable to other commonsense reasoners as that action in the first place. Searching for "why" 
people behave the way they do draws attention away from the "how." The aim of Garfinkel's endeavor can be understood as attempting to get at the following question: "how do social actors come to know, and know in common, what they are doing and the circumstances in which they are doing it?" (Heritage [1984] 1986:76).

This perspective also stands in contrast to SI, as Rawls (1985) explains:

The symbolic interactionist is more interested in the member's formulation of what they are doing (i.e., teaching, parenting, interviewing). The ethnomethodologist is more concerned with how the person actually organizes their actions in such a fashion that others can interpret their actions as amounting to teaching, parenting, or interviewing. (P. 131)

Analysis in $\mathrm{CA}$ is guided by the notion that talk "is better examined with respect to action than with respect to topicality, more for what it is doing than for what it is about" (Schegloff [2007] 2010:1).

In this study I use CA to examine how a doctor uses a figurative comparison during surgical consultations with breast cancer patients. Rigorous analytical treatment of figurative comparisons in this clinical context stands to reveal how people actually use them to get things done in medical consultations. As Schegloff and Sacks (1973) note, "a pervasively relevant issue (for participants) about utterances in conversation is 'why that now', a question whose analysis may [. . .] also be relevant to finding what 'that' is" (Schegloff and Sacks 1973:76). Therefore, I examine orderly features of figurative comparison in actual examples of talk, "not on the inside of an individual's head, and not in their statements about what is in their head" (Rawls 1985:131).

\section{A Conversation Analytic Approach to Figurative Expressions}

Conversation analytic studies have revealed some of the ways participants use figurative expressions as tools or devices in conversation. For example, Drew and Holt 
$(1988,1995,1998)$ discovered that people use figurative expressions as resources to accomplish topic shifts and topic termination in organized ways. Figurative expressions work to summarize and assess matters broached in preceding talk, thereby relaxing the topical constraints on subsequent talk. The basic organization of the procedure is as follows (Drew and Holt 1998:506):

1 Speaker A: Figurative summary

2 Speaker B: Agreement (or other expression of contiguity)

3 Speaker A: Agreement/confirmation

4 Speaker A/B: Introduces next topic

For example, in the extract below P's figurative expression (".hhh But $\underline{\underline{I}}$ think it'll iron itself out,") initiates a series of subsequent turns that leads to topic closure (Drew and Holt 1998:501):

(8) [JGI(S):X15:4-5]

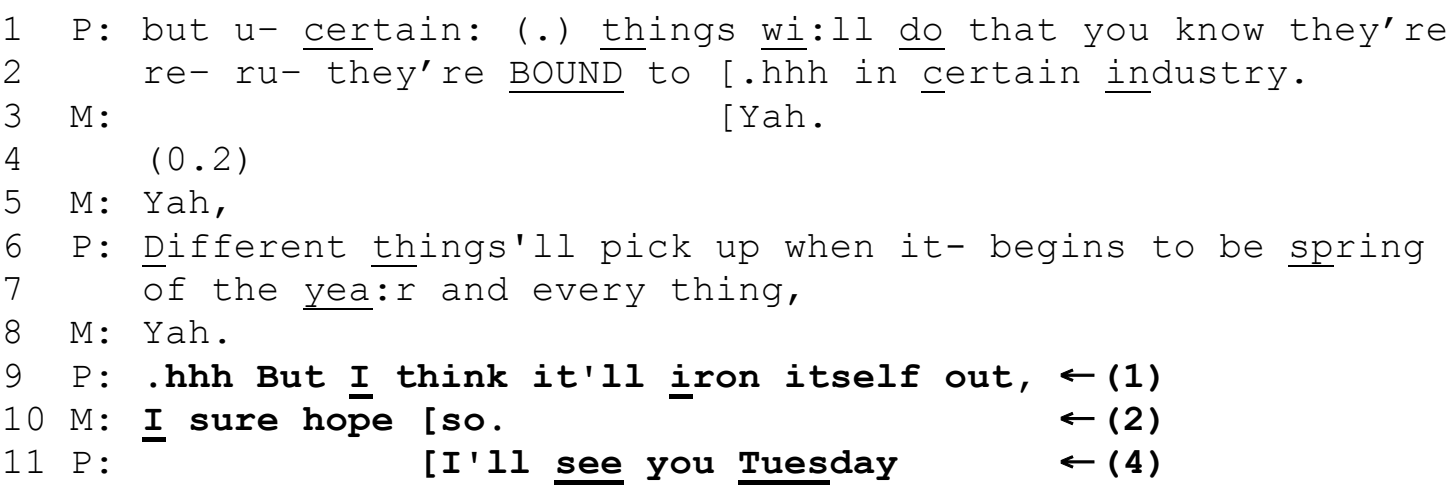

Figurative expressions can also be used to "pivot" from one topic to another (Holt and Drew 2005). Prior to the extract below, (Gill, Pomerantz, and Denvir 2010) a patient had been describing a symptom — swollen feet — to a doctor in some detail. The patient's figurative expression in lines 33-34 — "Think I gotta start using my umbrella or something." — initiates closure of talk concerning of the symptom by offering an assessment that downgrades it from a medical concern to a trivial matter, thereby making 
it easier for the doctor to transition to talk concerning a different symptom (Gill,

Pomerantz, and Denvir 2010:10):

(2) $[18: 1211(25: 27)]$

31 Pt: $\uparrow$ All the things that people have had all these years

32 and suddenly I get them and they fall on me you know.

33. hhh (0.8) Think I gotta start using my umbrella or

34 something.

$35 \quad(4.5)$

36 Dr: .hh Kay, then the other:- the other thing you

37 mentioned was: (.) you have (.) 'opain with

38 intercours:e. ${ }^{\circ}$

In contrast, I am interested in a different type of figurative expression, a figurative comparison, which, as I will show, does a different kind of interactional work entirely. I will focus on how one surgeon uses the analogy "cancer is like teenagers" as a resource to create an opportunity for patient participation and to educate them about how breast cancer behaves and how it should be treated. 


\section{CHAPTER III}

\section{DATA AND METHOD}

This project draws upon a corpus of existing, deidentified audio recordings of 13 preoperative surgical consultations between early-stage breast cancer patients and surgeons (13 patients, 4 surgeons). The consultations ranged in length from 14 to 60 minutes; there are more than 7 hours of recordings in the corpus. These data were collected in 2011-12 in two clinics located in the U.S. after gaining all necessary IRB approvals and the informed consent of all participants. ${ }^{2}$ Immediately after the consultations were recorded, all information that could potentially be used to identify participants, including, but not limited to, participants' names, locations, and affiliations, was deleted from the audiotapes. The recordings were then voice modified to further protect participants' identities.

There are four phases of CA research: (1) data acquisition, (2) transcription, (3) selective analysis, and (4) write-up (ten Have 1999). Having obtained the data and rough transcripts of the corpus, I decided to focus on the parts of the encounters where surgeons were providing details about the patients' cancers, and about cancer in general I transcribed these sections of the encounter in fine detail using conventions developed by Jefferson (1974; see Appendix A). Jefferson's system captures not only "what has been said, but also how it has been said" (ten Have 1999:76). Detailed transcriptions are key resources because they help the analyst dissect and unpack subtle details in episodes of 
interaction, details that the participants themselves use to make their actions meaningful and show their understanding of what others meant.

After I completed the detailed transcriptions, I worked through each of them systematically with reference to the five-step analytic process suggested by Pomerantz and Fehr (1997): (1) choose a sequence of interest; (2) identify and describe the action(s) being done in the sequence; (3) make note of how understandings of actions and options for subsequent turns are shaped by turn design; (4) reflect on the role of timing and speaker transition for participants' understandings of what is going on in a given sequence; and (5) think about how actions are achieved by participants such that identities and roles are created and recreated in the process.

For this analysis I drew upon four of the consultations where a surgeon employs a type of figurative comparison, the analogy "cancer is like teenagers," in conversations with four different patients. These encounters range in length from 19 to 45 minutes, and comprise 140 minutes of audio, total. With four cases, I cannot determine whether the practices I identify are typical. However, generalization is not my goal. Rather, I seek to identify and describe phenomena in these data so as to add them to an ever-growing collection of documented social practices in medical consultations, some of which may be typical and others, rare. For that reason my sample is not, and indeed need not be, random. Instead, this study began, as many CA studies do, with a "noticing" (ten Have 1999). As I reviewed the recordings for each of the 13 original consultations, I noticed that one of the four surgeons had a way of explaining cancer to patients that was distinctive: In each of the four consultations she explains what cancer is and how it behaves by deploying an analogy that compares it to teenagers. I then adopted a 
"specimen perspective" (ten Have 1999:50), which means that I worked through the data to collect 4 specimens of this phenomenon. These were largely located in the phase of the visit where the surgeon presented results from prior imaging studies (such as mammograms) and pathology reports (from biopsies). In the following section I describe the organization of activities in surgical consultations for early-stage breast cancer. Then I hone in on the specific interactional environment of interest for this research, and analyze how the surgeon uses the analogy in this context and what it accomplishes. 


\section{CHAPTER IV}

\section{ANALYSIS}

\section{Structure of the Surgical Consultation}

Surgical consultations for breast cancer have the following five activity phases: (1) opening, (2) findings, (3) treatment, (4) exam, and (5) plans (Gill 2014). In the opening phase of the consultation surgeons and patients introduce themselves and make small talk before broaching the discussion of the patient's cancer. The second phase, the one of specific interest for this research, includes reporting findings from prior imaging and biopsies. Although all of the patients were informed that they had breast cancer before their surgical consultation, in this phase the surgeons provided details about the nature of their cancer, such as type, stage, and grade. This is followed by the treatment phase wherein surgeons discuss treatment options and occasionally make recommendations. Surgeons leave the consultation room between phases three and four so the patient can change out of her clothes and into a medical gown in preparation for the physical examination, which comprises the fourth phase of the consultation. After surgeons have examined the patient the consultation moves into the fifth and final phase_-discussing plans for treatment and determining the date of surgery (Gill 2014).

\section{The Focal Phenomenon and Its Interactional Environment}

My analysis focuses on activities in phase two — findings — where surgeons

draw upon pathology reports, mammograms, and visual aids to describe the type, stage, 
and grade of patients' cancer. I focus on a procedure one surgeon uses to explain what cancer is while (1) simultaneously providing an opportunity for patient participation and (2) creating an interactional environment stocked with material that she can use to describe specific features of the disease, including how it behaves, its ideal treatment, and barriers to ideal treatment. The basic structure of the interactional environment within which the phenomenon occurs is as follows:

(A) Doctor reports the official diagnosis;

(B) Doctor describes the anatomy of the breast, which provides a foundation for understanding $(\mathrm{C})$;

(C) Doctor reports that there are two types of breast cancer - ductal and lobular;

(D) Doctor describes what cancer is - cells that are growing abnormally;

(E) Doctor offers a figurative comparison: cancer is like teenagers;

(F) Doctor describes how cancer is like teenagers;

(G) Doctor mobilizes materials from (E) - (F) to do additional work.

\section{Reporting the}

Diagnosis (A)

\section{Unpacking} the Diagnosis (B)-(F)

\section{Mobilizing the Analogy (G)}

In this analysis I will present four separate instances of this procedure in action. In each case I focus on how the analogy arises in a particular social context and what it makes possible, interactionally. 


\section{Case 1}

The patient in Case 1 has invasive ductal cancer. Among those in the consultation room are the surgeon, the patient, and several members of the patient's family. This extract begins just after the surgeon has presented findings from the patient's diagnostic imaging tests. In Extract 1 the surgeon shifts her attention to the pathology report, which contains findings from three separate biopsies - two from the patient's left breast and one from a swollen lymph node located in the patient's left armpit.

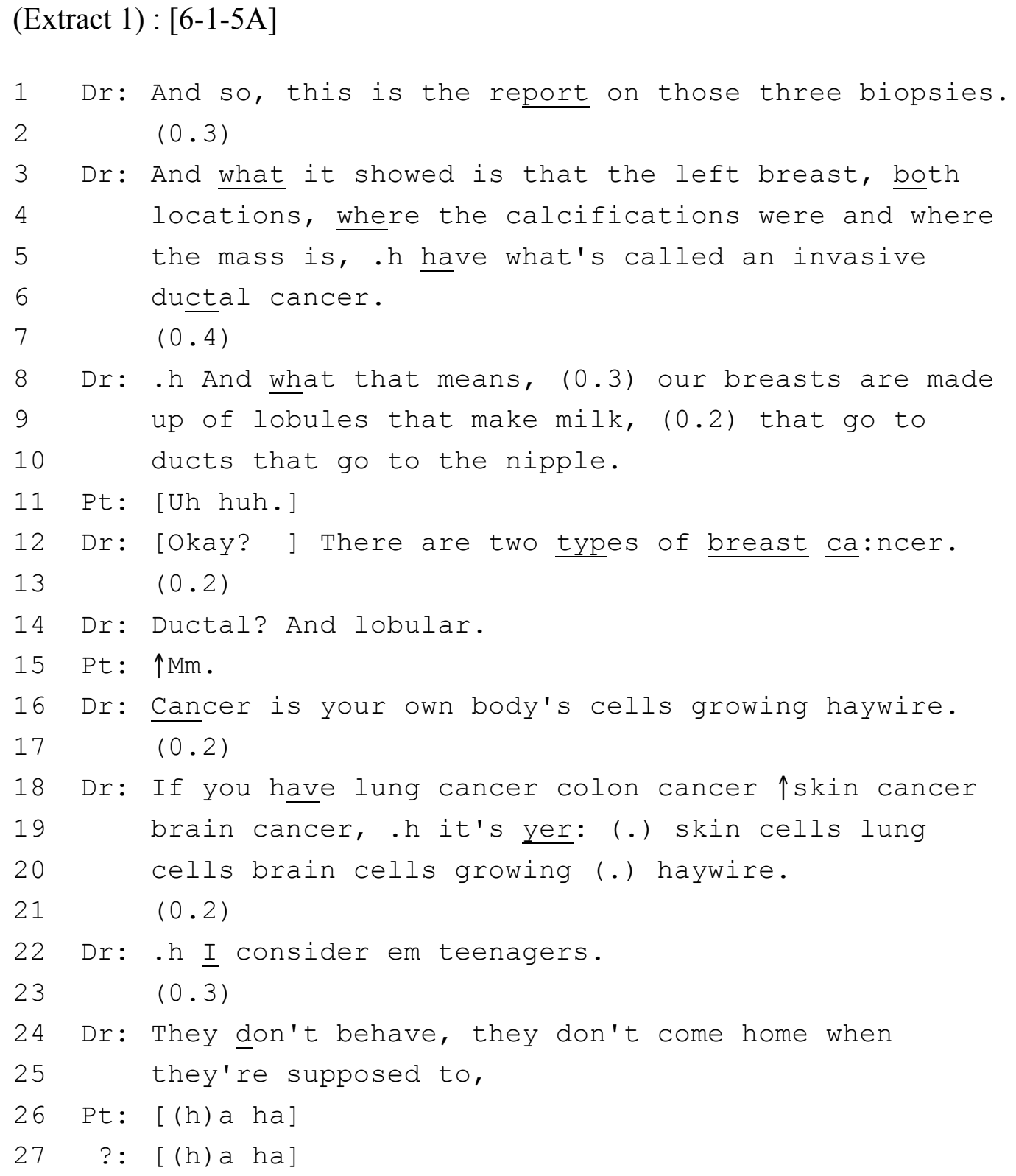




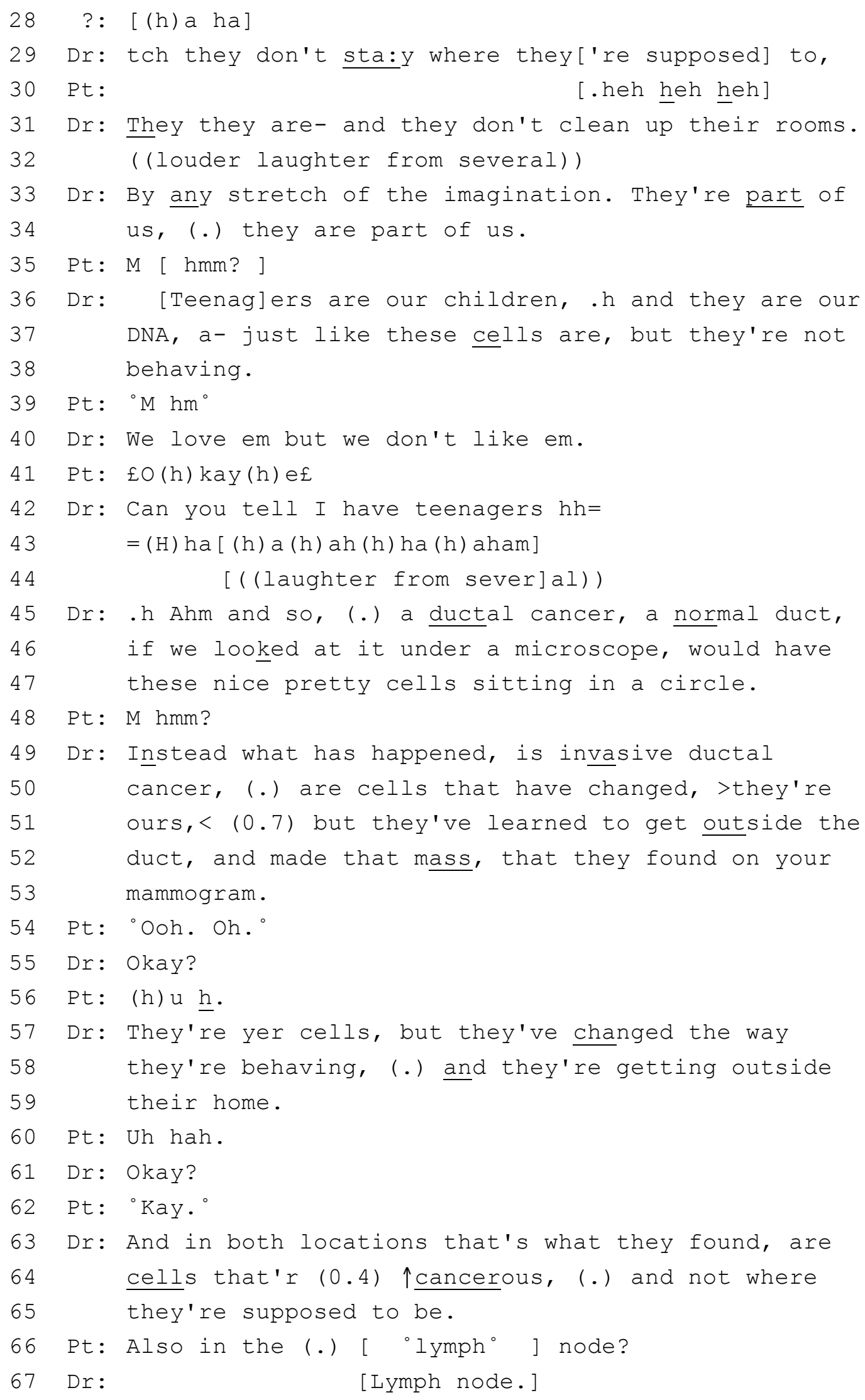




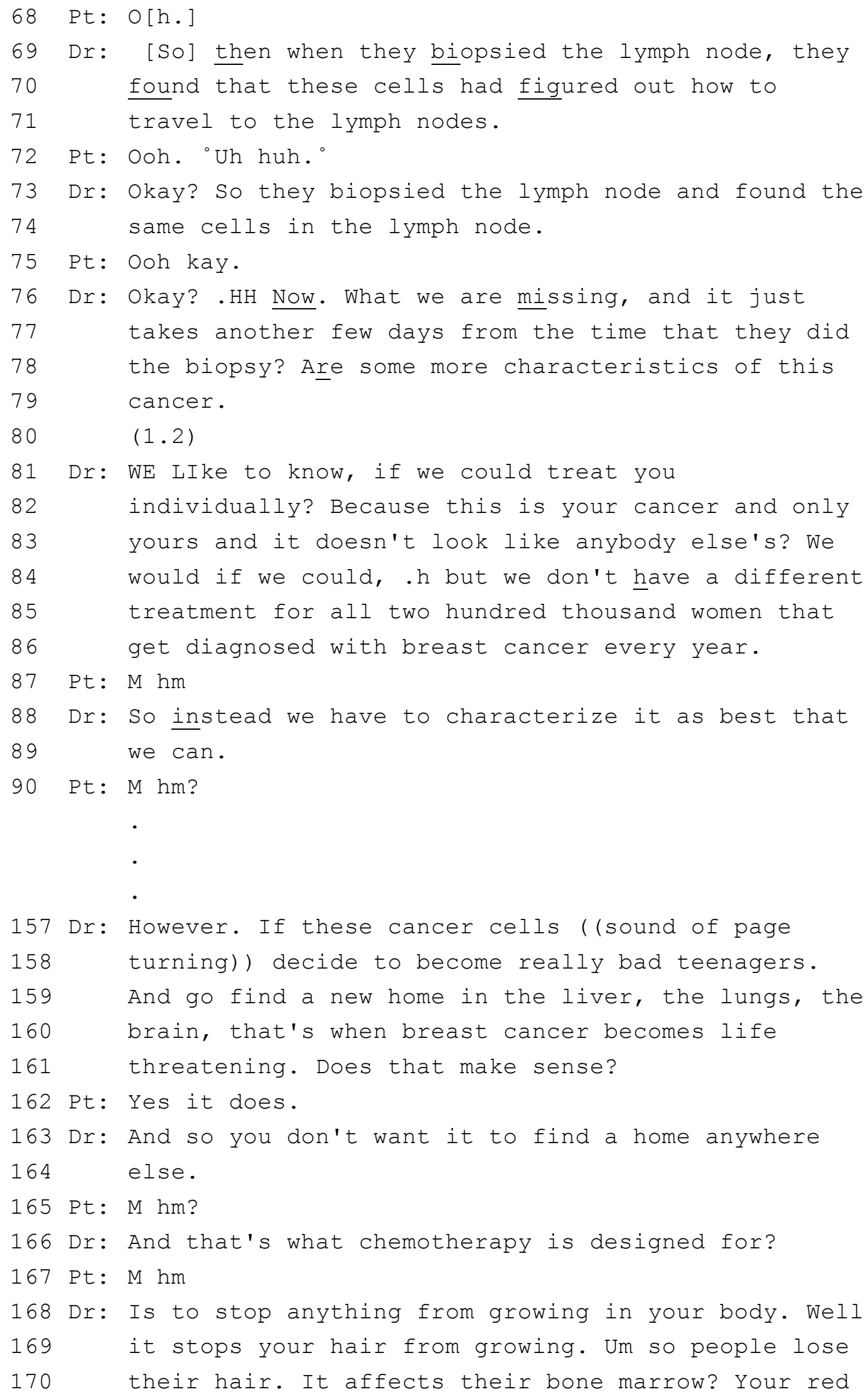




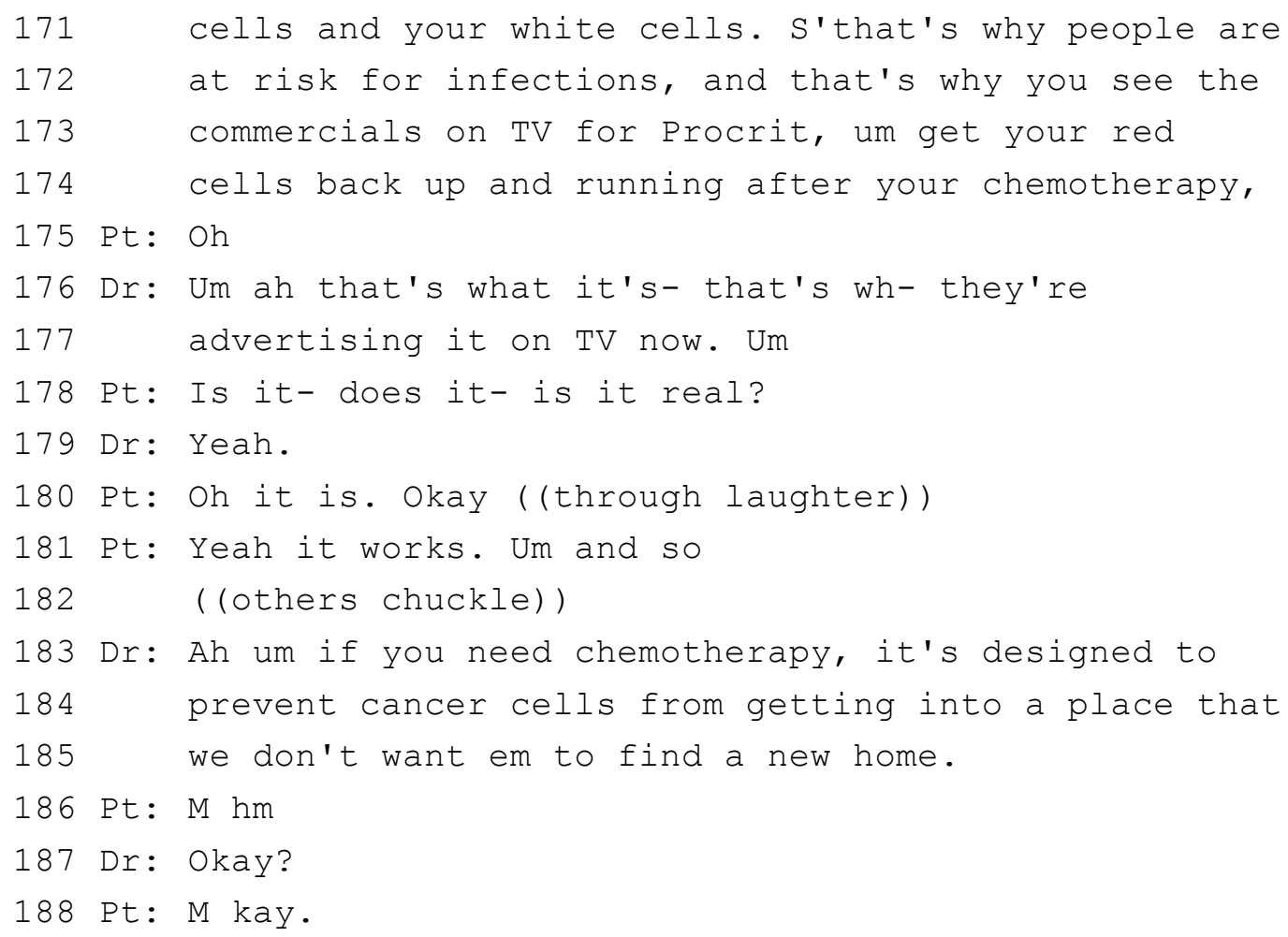

After broaching the patient's pathology report (line 1, below), and noting that it contains findings from each of the patient's three biopsies, the surgeon first orients to those taken from the patient's breast (lines 3-5). At (A) the surgeon reports that the biopsies taken from the patient's left breast "have what's called an invasive ductal cancer." (1a) : $[6-1-5 \mathrm{~A}]$

1 Dr: And so, this is the report on those three biopsies. $2 \quad(0.3)$

3 Dr: And what it showed is that the left breast, both

4 locations, where the calcifications were and where

5 the mass is, .h have what's called an invasive $\leftarrow$ (A)

6 ductal cancer.

$7 \quad(0.4)$

8 Dr: .h And what that means, (0.3) our breasts are made

9 up of lobules that make milk, (0.2) that go to $\leftarrow$ (B) 10 ducts that go to the nipple. 


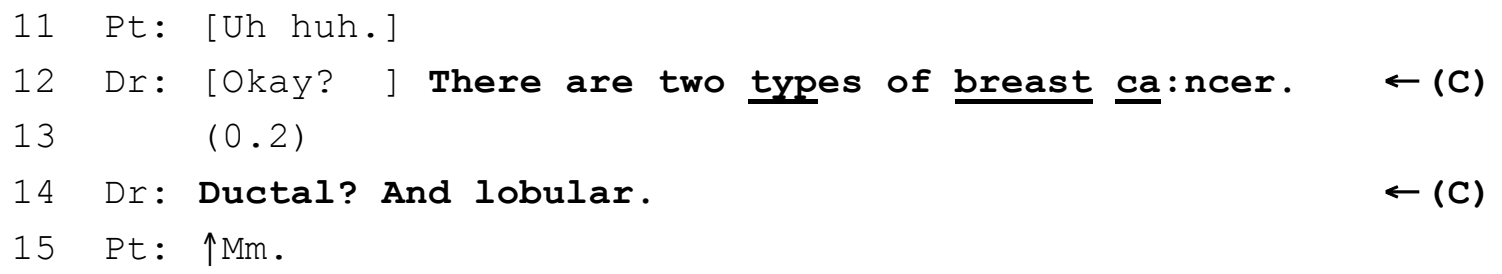

After the surgeon reports the patient's clinical diagnosis (A), she begins to unpack the diagnosis. She extends her turn in line 8 with a pre-explanation ("And what that means,") followed by the next component of her narrative — an anatomical description of the breast (B). In line 11 the patient orients to the surgeon's prior utterance as a complete "chunk of information" (Heritage 1984:301) by producing an affirmative "Uh huh."

After describing the anatomy of the breast to the patient, the surgeon notes that there are two types of breast cancer - ductal and lobular (C). Notice how (B), "our breasts are made up of lobules that make milk, (0.2) that go to ducts that go to the nipple", provides a foundation for understanding the information she provides in (C), cancer starts in two specific parts of the breast. The patient registers this information in line 15 with "^Mm." The patient's utterance has intonation from high to low, like the utterance "oh," which is used to indicate that the speaker has undergone some sort of "change of state" (Heritage 1984) in her knowledge or understanding.

Having established that the patient has invasive ductal cancer and that ductal cancer is one of two main types of breast cancer, the surgeon describes what cancer is (Extract 1b, line 16): "Cancer is your own body's cells growing haywire" (D). The surgeon then extends her turn in lines 18-20 (Extract 1a, above) with a description that utilizes paired types, which emphasize the notion that cancer occurs at the cellular level. Moreover, she indicates that a cancer's type is determined by the type of cells that are behaving abnormally (D). 


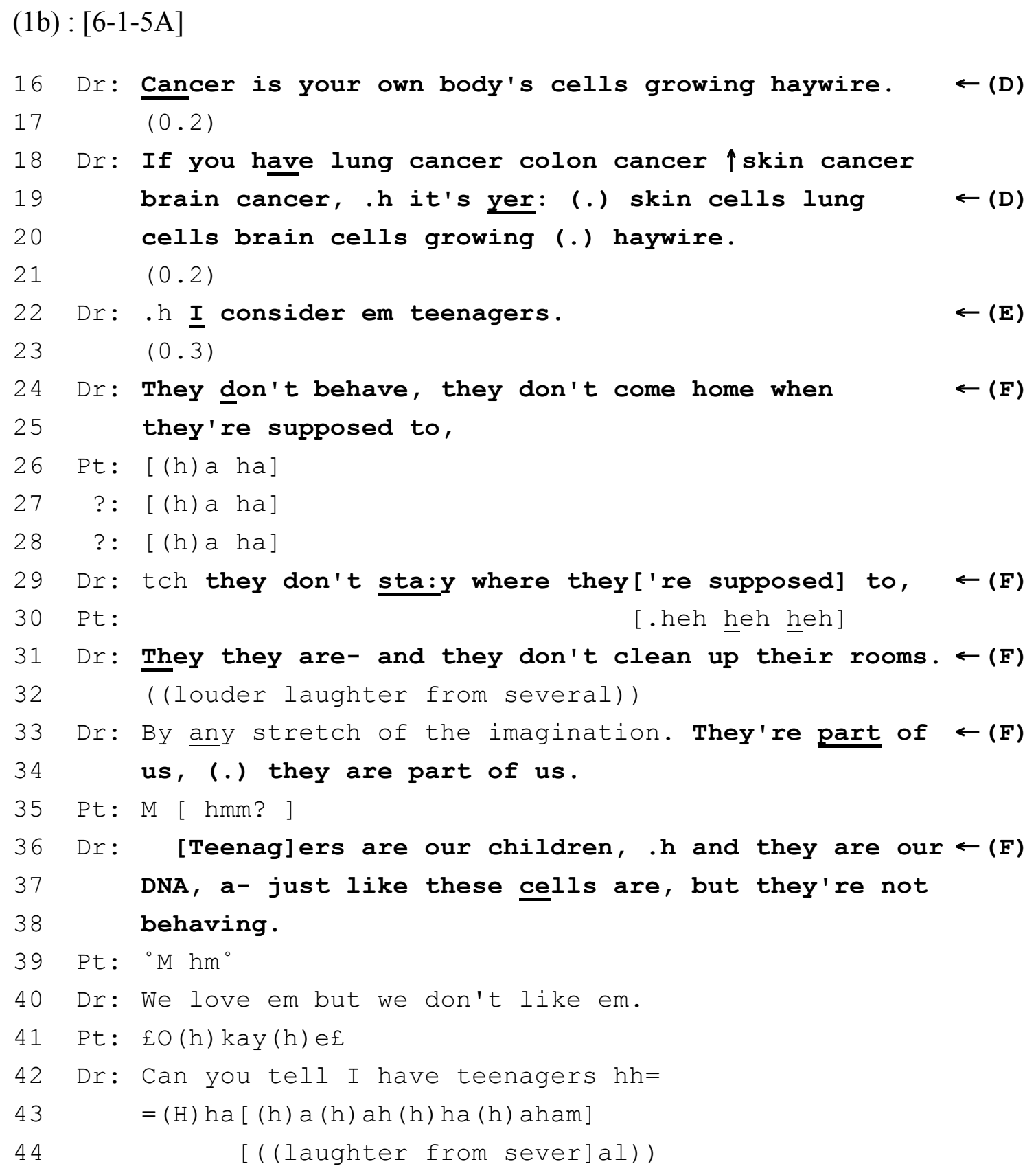

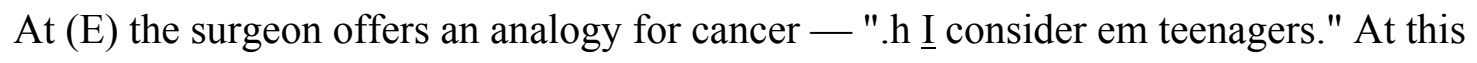
point "em" is constituted, retrospectively, by the surgeon's previous utterance, which makes the referent intelligible as "cells growing haywire", i.e., cancer (lines 16 and 20). Interestingly, the surgeon presents this analogy in a markedly different way than she did the description that preceded it: When the surgeon presented her literal description of 
cancer she structured it as an objective report, i.e., "Cancer is your own body's cells growing haywire" (line 16); in contrast, when the surgeon presents the figurative analogy she offers it up to the patient (and her family) as a personal opinion, with "I consider em teenagers" (line 22).

After a brief (0.3) silence in line 23, the surgeon delivers the first two items of a list designed to substantiate her analogy — "They don't behave, they don't come home when they're supposed to," (lines 24-25). As soon as the surgeon completes her second list item the patient and at least two other participants deliver simultaneous laughter (lines 26-28). This simultaneous response may be related to the recognizably of list construction (Jefferson 1990). That is, lists are recognizably underway upon the delivery of a second item. The surgeon's first two list items both begin with a referent ("they"), name and reprove an example of conduct associated with that referent ("don't behave," "don't come home when they're supposed to"), and end with continuing intonation, which makes it hearable as "listing." When the surgeon's utterances become recognizable as "listing" her list's project becomes clear — procuring recipients' participation. That hearers of a list-in-progress can recognize it as such is significant because it makes it easier for them to become more actively involved in its project. Recipients' short, uniform laugh particles directly after the surgeon's second list item are important because, "given two items so far, a recipient can see that a third will occur" (Jefferson 1990:73). So by producing short, plosive laugh particles, recipients align with the surgeon's project and allow her to continue. The patient alone receipts the surgeon's third list item ("they don't sta:y where they're supposed to, line 29) with laughter. However, the surgeon's stretched "sta:y" projects another item to come, as does her continuing intonation. But the 
surgeon's fourth and final list item is met with much louder laughter from several participants. This is likely due to the surgeon's prefacing of the final item with "and," which clearly projects a precise list completion point. Note the work that the surgeon does to show recipients that this list item is the final one in the series. The surgeon begins her utterance in line 31 with "They they are-" then initiates a repair by restarting her utterance, but this time prefaced with "and" to project list termination — "and they don't clean up their rooms" (line 31).

The point to emphasize here, is that listing invites participation in a variety of ways (Atkinson 1985). List construction is a valuable resource for speakers and listeners alike (Jefferson 1990); by constructing a list in this particular sequential environment, the surgeon invites patients (and their families) to display a reaction to the analogy, but does not outwardly require them to do so.

Significantly, the surgeon's analogy elicits laughter from the patient and her family (and not just here, but as I will soon show, it regularly does so). When the surgeon substantiates her analogy at (F), she outlines teenage behaviors from the perspective of an "adult who knows better," describing (in a reproving manner) the specific ways that teenagers break the rules. In so doing, she effectively asks the patient (and her family) to see these familiar characteristics in cancer, an entity that is commonly known to be reviled and feared. This blatantly incongruous comparison is what makes the surgeon's analogy "laughable." Teenagers, "as everyone knows," are cheeky and immature, while cancer, "as everyone knows," is scary. It is not that teenagers' behaviors are funny per se, but when the surgeon attaches these behaviors to a scary, non-human entity she creates an unexpected match that works to elicit laughter. 
Having offered an analogy that likened cancer to teenagers, and having described how exactly cancer is like teenagers, the surgeon then mobilizes the analogy to explain what invasive cancer is, how it behaves, and what it means for treatment $(\mathrm{G})$ :

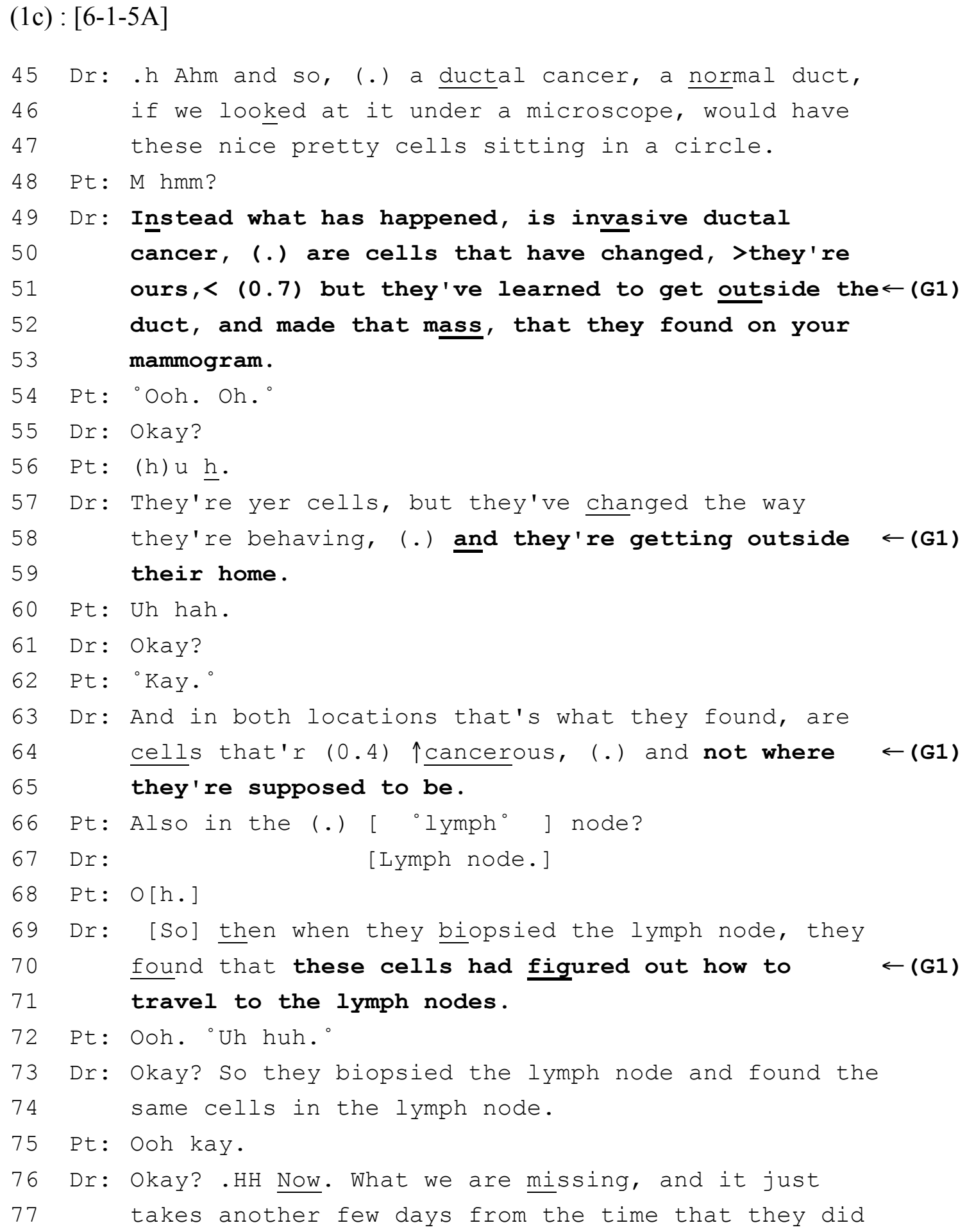




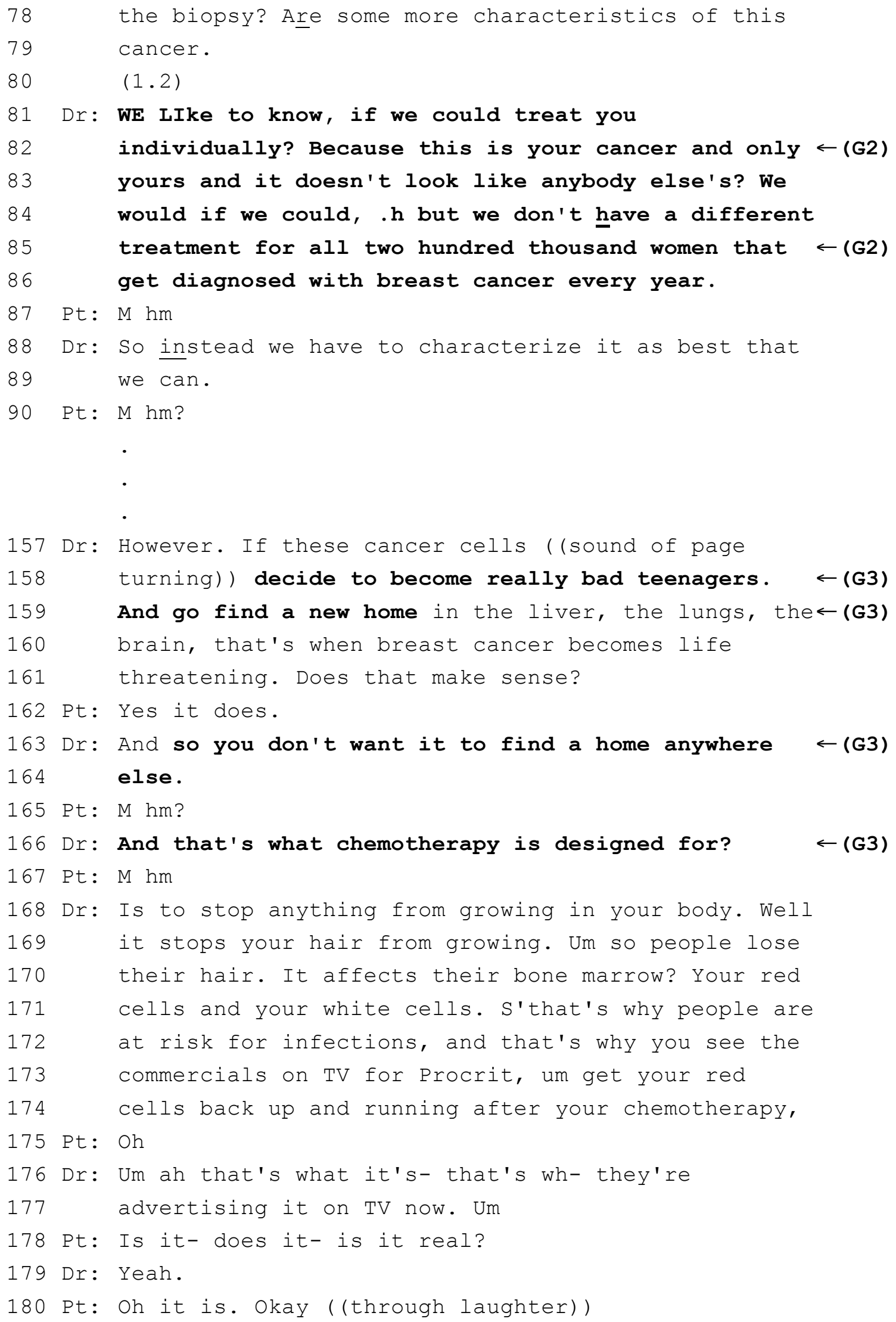




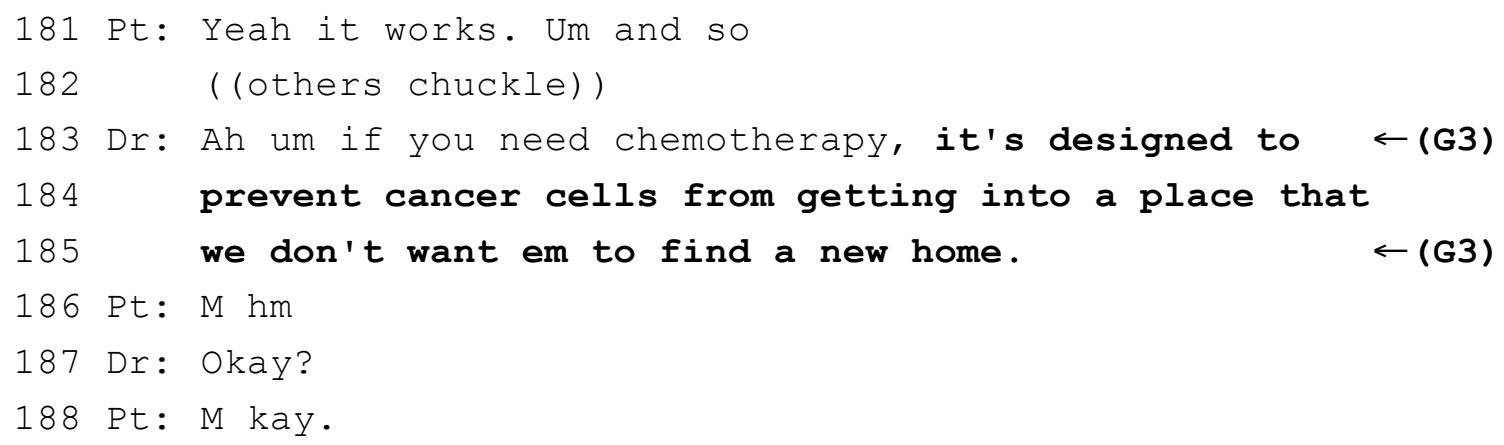

In lines 45-65 the surgeon uses the behaviors and attributes that she established when substantiating her analogy in (F) to explain what invasive cancer is (G1). The surgeon emphasizes this point on three separate occasions: The patient's ductal cells have "learned" how to get outside of their "home" (lines 58-59), they are not where they are "supposed to be" (lines 64-71), and now they have "figured out" (lines 70-71) how to get to the patient's lymph nodes.

The surgeon then mobilizes those same materials to explain the implications for treatment (G2) (lines 81-86). Because the patient's cancer is entirely unique ("this is your cancer and only yours and it doesn't look like anybody else's") it should ideally be treated as such. However, given the current state of medical knowledge, this is not possible. Thus, the analogy assists the doctor in explaining that there is a gap between the ideal treatment for breast cancer and what is currently available.

The surgeon also uses materials from (E)-(F) to describe why chemotherapy is recommended, as well as how chemotherapy works (G3), (lines 157-185). She starts by explaining that ductal cancer can become life-threatening if they "decide to become really bad teenagers" (line 158) and "find a new home" (line 159) in vital organs. The surgeon then explains that chemotherapy is designed to prevent this from happening (lines 183185). 


\section{Case 2}

The patient in this case has ductal carcinoma in situ (DCIS), a condition that some consider to be pre-cancer. A medical resident is also in the room. After reviewing the patient's diagnostic imaging the surgeon turns her attention to the pathology report and launches the next task — presenting and unpacking the diagnosis:

(Extract 2) : [3-1-3A]

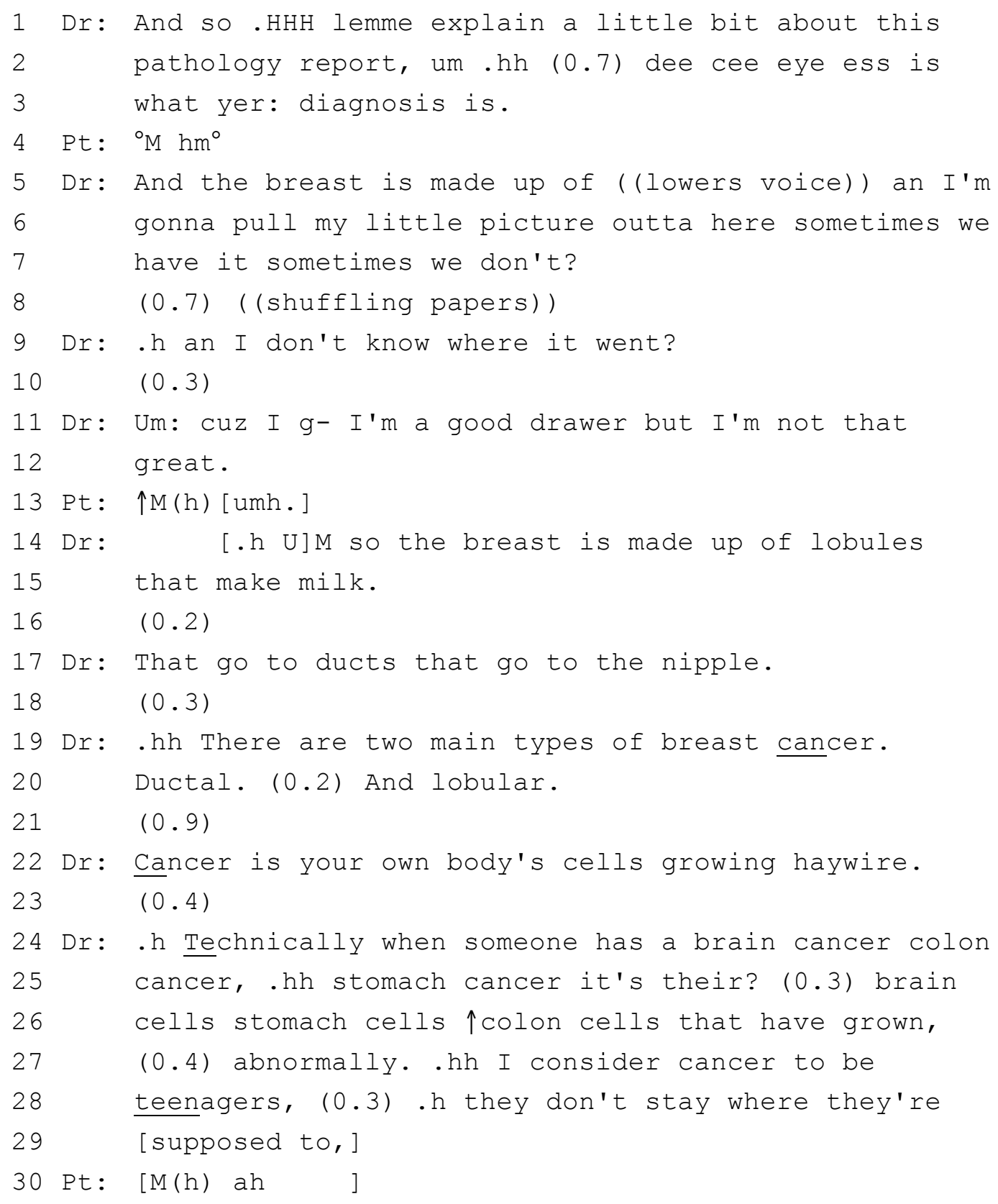




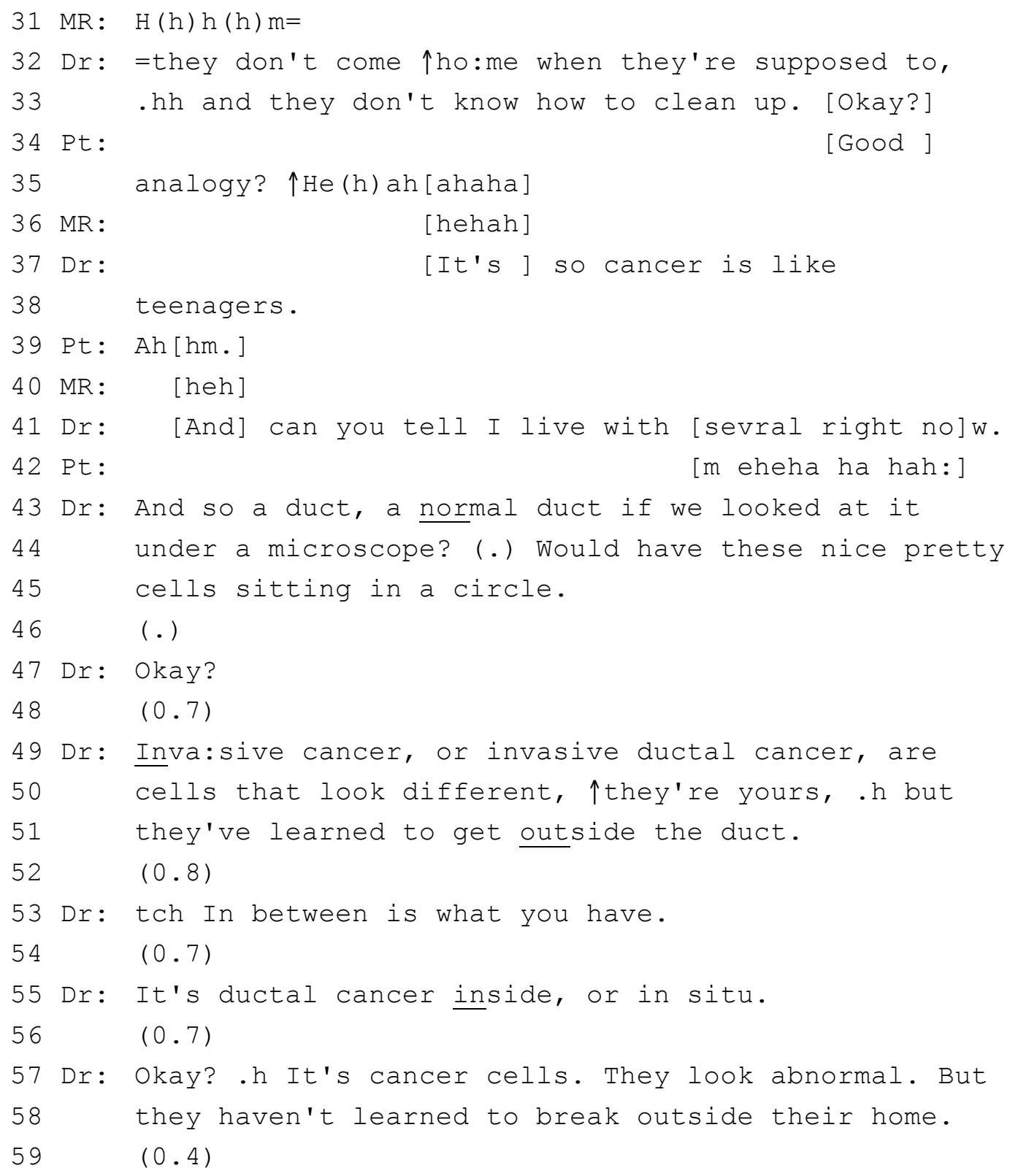

At (A) the surgeon begins by reporting the patient's official clinical diagnosis (Extract 2a, below). The patient receipts the surgeon's report of the official diagnosis (A) with a soft-spoken continuer, "० ${ }^{\mathrm{M} \mathrm{hm}}{ }^{\circ}$, in line 4 that acknowledges this component of the surgeon's narrative and allows her to continue: 


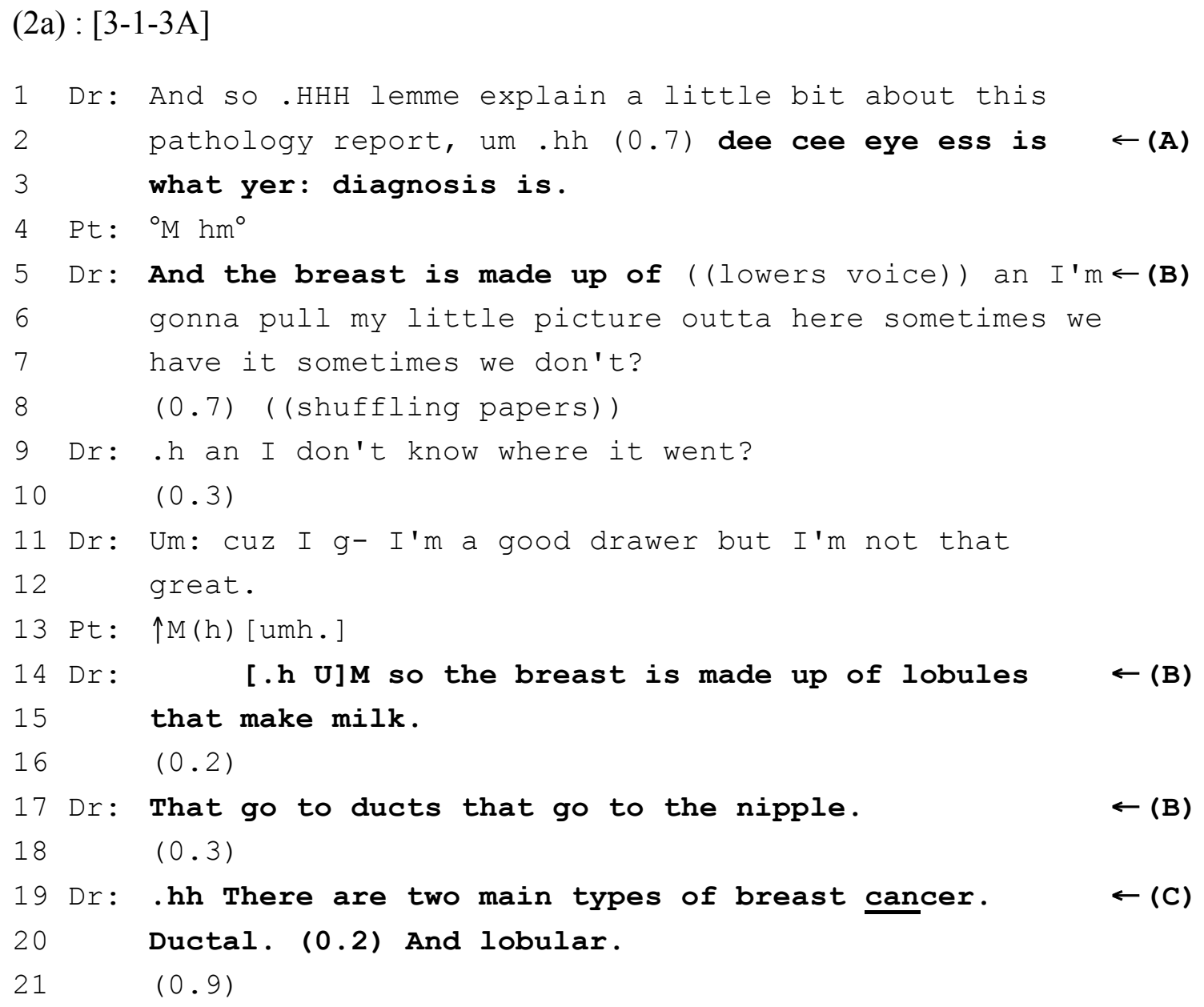

The surgeon then begins to unpack the diagnosis by projecting the next component of her narrative - (B) a basic overview of breast anatomy. After briefly breaking off her narrative to search for a visual aid (lines 5-12), the surgeon launches her description again by recycling the beginning of her utterance ("the breast is made up of") in line 14 before advancing her anatomical description of the breast (B). The surgeon's overview of breast anatomy is, by virtue of its sequential position, hearable as (or as projecting) an explanation of the patient's diagnosis.

After establishing that "the breast is made up of lobules that make milk" (lines 1415) and milk goes "to ducts that go to the nipple" (line 17), the surgeon continues 
unpacking the diagnosis, reporting that there are two types of breast cancer $(\mathrm{C})$. One of the most fundamental sensemaking resources available to people is sequential placement: People largely interpret the meaning of utterances based on their sequential position.

Here, as before, the surgeon's presentation of the breast's anatomy (B) provides materials that facilitate her subsequent explanation about what types of cancer exist (C).

Having reported the patient's clinical diagnosis (A), and having begun to unpack it by explaining the breast's anatomy (B), and reporting the two most common types of breast cancer (C), the surgeon describes what cancer is (D) (Extract 2b, below).

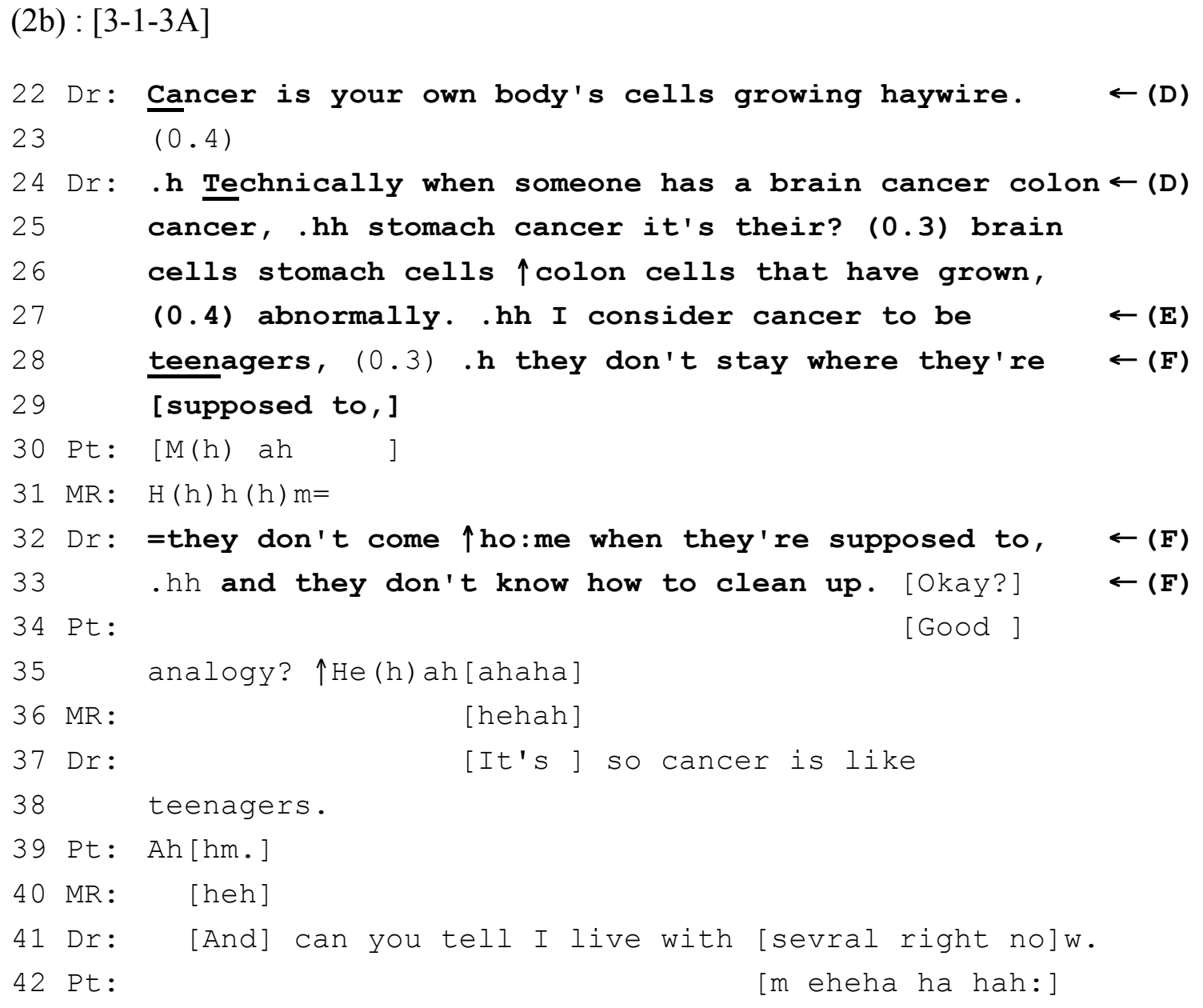


After the surgeon delivers a description of cancer (D) as "your own body's cells growing haywire", she continues by listing three different types of cancer - brain, colon, and stomach - then indicating that each type can be attributed to cells that have "grown abnormally" in those locations (lines 24-27). The surgeon works to emphasize and support a view of cancer as individual, via the referents "your own" (body's cells) and "it's their" (cells).

At (E) the surgeon offers an analogy for cancer - "I consider cancer to be teenagers," (lines 27-28). She then substantiates her assertion (F) by listing quirky behaviors that teenagers are commonly thought to engage in (lines 28-29 and 32-33). In this case the patient produces laughter at a possible completion point projected by the surgeon's first list item (line 30). It is important to note that at this point the surgeon's "they don't stay where they're" (line 28) is not yet recognizable as "listing." In fact, since the surgeon's first list item follows directly from the analogy itself, which the surgeon delivered with continuing intonation, the patient laughs at the point where a completion point is projected. However, the surgeon delivers her first item with continuing intonation "supposed to," (line 29) and extends her turn in line 32 with a second item, "they don't come $\uparrow$ ho:me when they're supposed to," thereby making it recognizable as "listing." This is important because, "given two items so far, a recipient can see that a third will occur and that upon its occurrence utterance completion can have occurred whereupon it will be his [or her] turn to talk" (Jefferson 1990:73). By constructing a list in this particular sequential environment, the surgeon invites the patient to display a reaction to the analogy, which the patient does in lines 34-35 with a positive assessment followed by laughter — "Good analogy $\uparrow \mathrm{He}(\mathrm{h})$ ahahaha." 
It is important to note that the surgeon's analogy + list substantiation do not invite patients to display just any reaction to the analogy, it invites patients to display affiliation. The surgeon's list items contain the referent "they," which is hearable as referring to "teenagers" based on the surgeon's positioning of the list directly after her analogy. Additionally, as in Case 1, the surgeon's list items reflect a particular authoritative, and paternalistic, orientation to teenagers. In this way the surgeon invites the patient to draw upon a commonsense understanding of teenagers as cheeky, misbehaving rabble-rousers. Here, also consistent with Case 1, the comparison between two otherwise starkly contrasting entities, cancer and teenagers, elicits laughter from the patient (line 30) and the medical resident in attendance (line 31), thereby creating the appearance of rapport.

In Extract 2c, below, the surgeon starts by presenting a description of a normal duct (lines 43-45), then contrasts it with a description of a duct with invasive cancer (lines 49-51) before she mobilizes the analogy to explain the patient's diagnosis (DCIS) to her $(\mathrm{G})$.

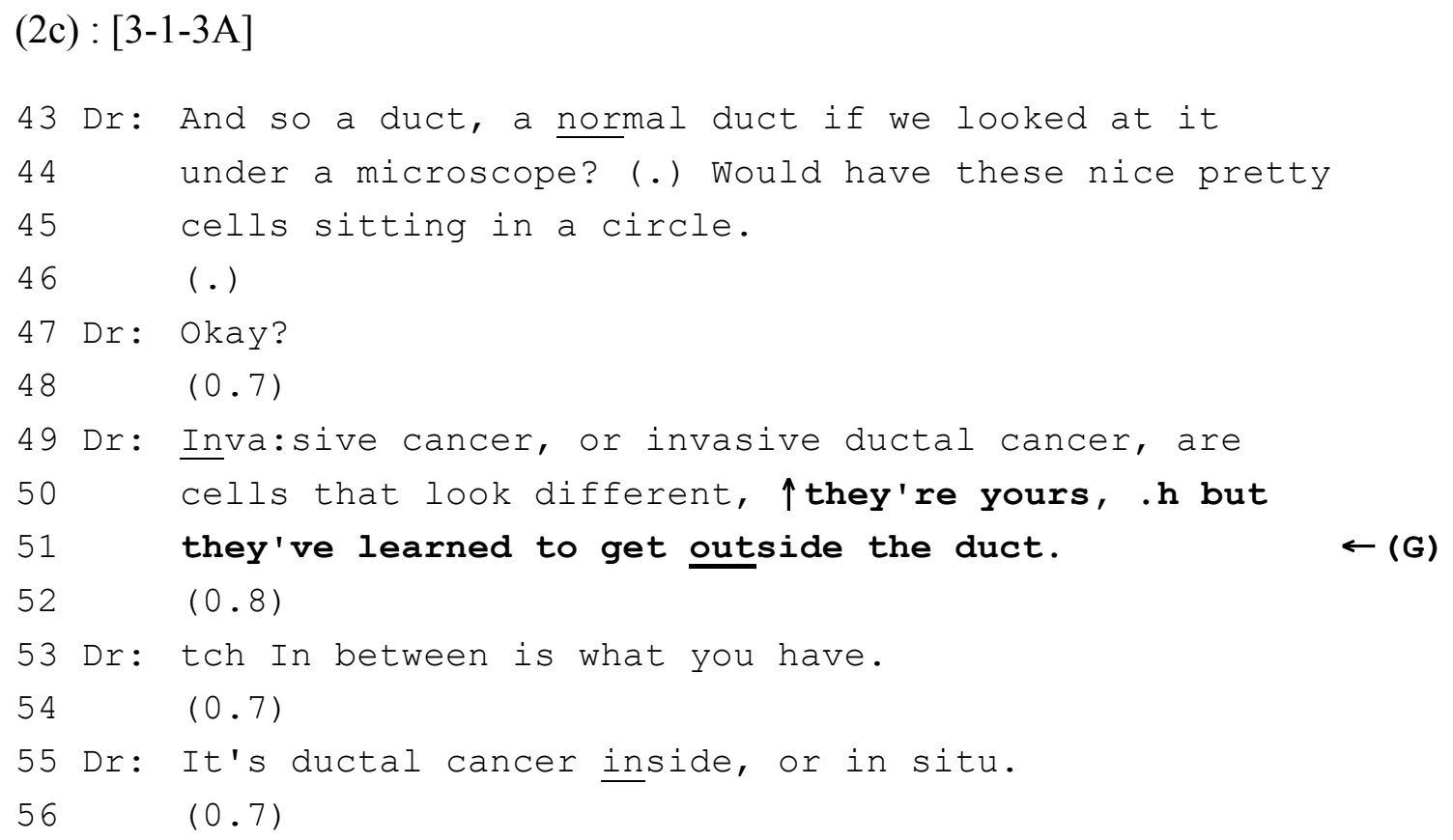


57 Dr: Okay? .h It's cancer cells. They look abnormal. But

58 they haven't learned to break outside their home. $\leftarrow(G)$

$59 \quad(0.4)$

In line 51 (Extract 2c, above), the surgeon draws upon one of the "teenage" attributes of cancer to explain the difference between normal ductal cells and invasive ductal cancer (G) - the latter have "learned to get outside the duct" (line 51). In turn, this allows the surgeon to pinpoint the type of cancer this patient has in line 53: "In between is what you have." She then reiterates this in line 55 ("It's ductal cancer inside, or in situ") and in line 57 ("they haven't learned to break outside their home").

Having established the two extremes (non-cancer and invasive cancer), the surgeon draws upon her description of what makes ductal cells invasive (i.e., the fact that they have learned to get outside of the duct), to show the patient that her "cancer cells don't know how to break outside," (lines 99-100). To accomplish this, the surgeon utilizes an attribute she worked to establish in components (E)-(F) of her narrative - cancer, like teenagers, does not stay where it is supposed to — to accentuate the key difference between cancer that is invasive, and the patient's cancer, which is non-invasive.

\section{Case 3}

In Case 3, the patient is seeking a second opinion, having previously met with a different surgeon located in elsewhere in the U.S. She is accompanied by her husband. In the following extract, the surgeon, who has just finished presenting the patient's diagnostic imaging results, moves to discuss the findings from the patient's biopsy (Extract 3, below): 


\section{(Extract 3$):[1-1-1 \mathrm{~A}]$}

1 Dr: Okay? .h Um SO, looking at your (.) path report 2 this is $(0.4)$ you know (.) your copy of it. Is

3 my understanding?

4 Pt: That's for you. I- [have extr]as

5 Dr: [Oh I have it]

6 Pt: Ok [a y $]$

7 Dr: [I h]ave it. I .h I'm happy to write on it

8 though [Jus]t to show you .hh um (0.5) THAT um=

9 Pt: Su[re]

10 Dr: $=. h$ LEFT BREAST THREE O'CLOCK (m-) $y^{\prime}$ know

11 obviously I always check to make sure it's you,

12 .h invasive ductal cancer, member two types of

13 breast cancer ductal and lobular

14 Pt: $\mathrm{M} \mathrm{hm}$

15 Dr: .Hh Um (0.6) an I just- we usually have a

16 little picture of it. (0.6) ((shufflingpapers))

17 Um ductal cancer.$h$ are cells that are growing

18 inside the duct, that then learn to invade

19 outside their home, I like to consider cancer

20 teenagers[.h Um they're not obeying the] rules,

$21 \mathrm{Hu}: \quad[\mathrm{hh}(\underline{\mathrm{h}}) \operatorname{um}(\underline{\mathrm{h}}) \operatorname{um}(\underline{\mathrm{h}}) \mathrm{um}(\underline{\mathrm{h}}) \mathrm{mm} \quad \mathrm{hmmm}]$

$22 \mathrm{Hu}:(\mathrm{h}) \mathrm{m}-$

23 Dr: .h they do not stay where they're supposed

24 t $[0$, a]nd they do not come=

$25 \mathrm{Hu}: \quad[(\mathrm{h}) \mathrm{m}-]$

26 Dr: = $\uparrow$ ho: :m[e when they're supposed to.]

27 Pt: [heh hueh hehh hu $\downarrow$ huheu ]

$28 \mathrm{Hu}$ : [huhumuh] [huhmm ]

29 Dr: [huh huh] [huah ]

30 Pt: $\quad[>$ An they<] h:ang out together.

$31 \mathrm{Hu}$ : [ $\uparrow$ huhah hah $\uparrow$ haeheh heheh heh ]

32 Dr: [.h And they HA:NG OUT that is] ex- I haven't

33 use [d th] [at $£$ be $(h) f(h)$ or $(h) e::$ ? ] =

$34 \mathrm{Hu}$ [ [ $\uparrow$ Hah] [hah $\uparrow$ haeheh heheh heh]

35 Pt: [ $\uparrow(h)$ eh heh hEH HEH HEH] .H $\downarrow$ heh-

36 Dr: =.HH That is exactly right.

37 Pt: (h) eh- (h) eh

38 Dr: Ahem [ca- ] cancer er are. HH we love em?= 39 Pt: $\quad[(\mathrm{Ka}-)]$ 


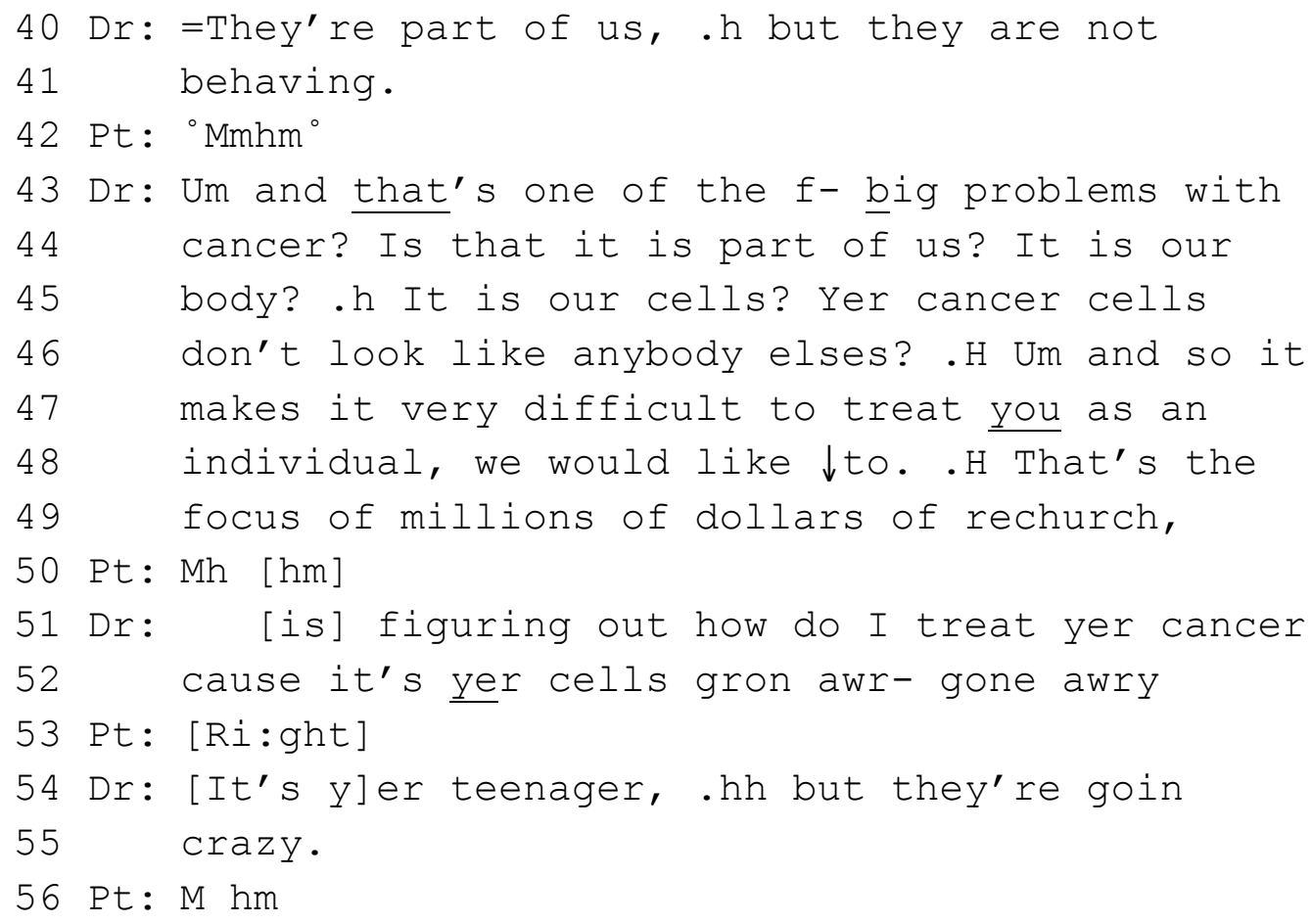

After briefly dealing with matters related to the patient's copy of the pathology report (lines 1-9, above), the surgeon uses it as a resource to organize this section of the consultation. She begins by emphasizing particular details of the report in stepwise fashion, first by reporting the biopsy location (line 10), then reporting that she has checked that this biopsy report is in fact, the patient's (lines 10-11). The surgeon's utterance, "y’know obviously I always check to make sure it's you," may be a way of displaying her orientation to a common patient concern — medical mix-ups.

Next the surgeon reports the patient's official diagnosis (".h invasive ductal cancer"). However, in this case the surgeon does not describe the anatomy of the breast (B). Instead, she moves straight to (C) with her next utterance, ("member two types of breast cancer ductal and lobular"): 
(3a) : [1-1-1A]

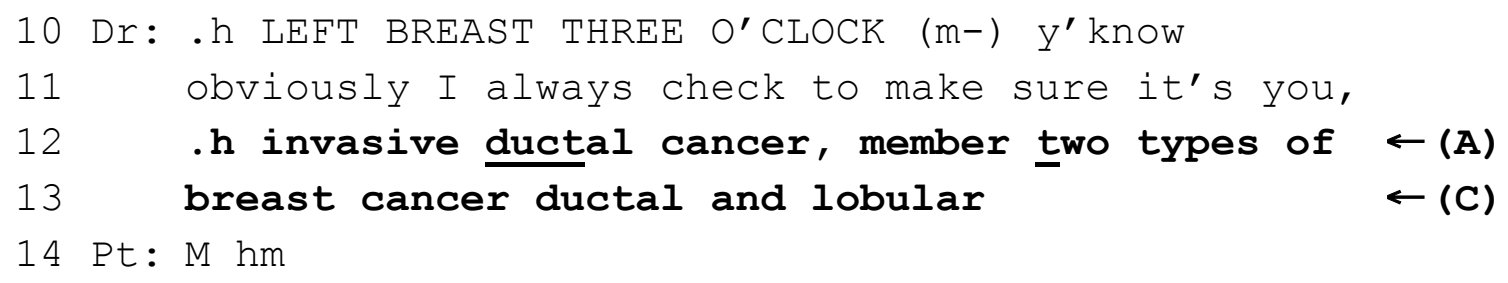

While the surgeon does not describe the anatomy of the breast to this patient, she does preface her utterance with "member" (hearable as "remember"), marking the subsequent information as a review, rather than as "news" - i.e., she orients to this patient as someone who has heard this information before. Since the surgeon orients to (C) as a review for this particular patient, it is possible that (B) was omitted for the same reason. That is, when the surgeon orients to the patient as someone who already knows what types of breast cancer are possible (ductal and lobular), she may also implicitly treat the patient's tacit understanding of the breast's anatomy as sufficient for all practical purposes (Garfinkel 1967). The surgeon also displays her orientation to the patient's epistemic status by using anatomical terms here, and marking them as already familiar to the patient. ${ }^{3}$ The patient's "M hm" in line 14 acknowledges the surgeon's turn with a minimal turn design that allows her to continue.

Having established that the patient has invasive ductal cancer and that ductal cancer is one of two main types of breast cancer, the surgeon describes what cancer consists of (Extract 3b, below): "cells that are growing inside the duct, that then learn to invade outside their home" (D).

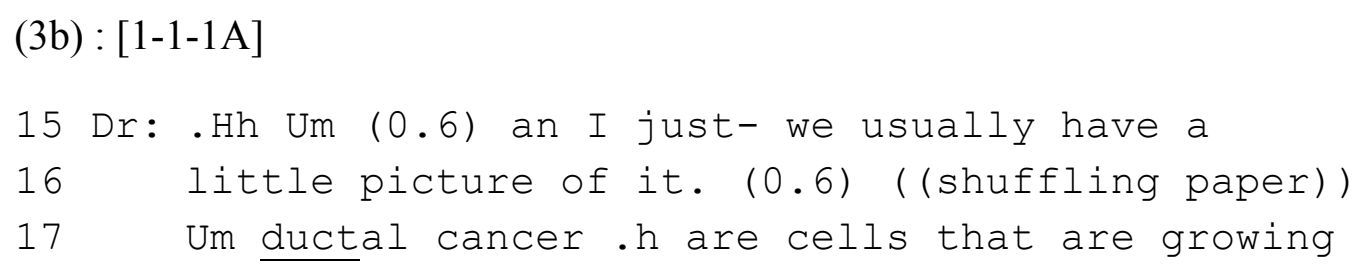




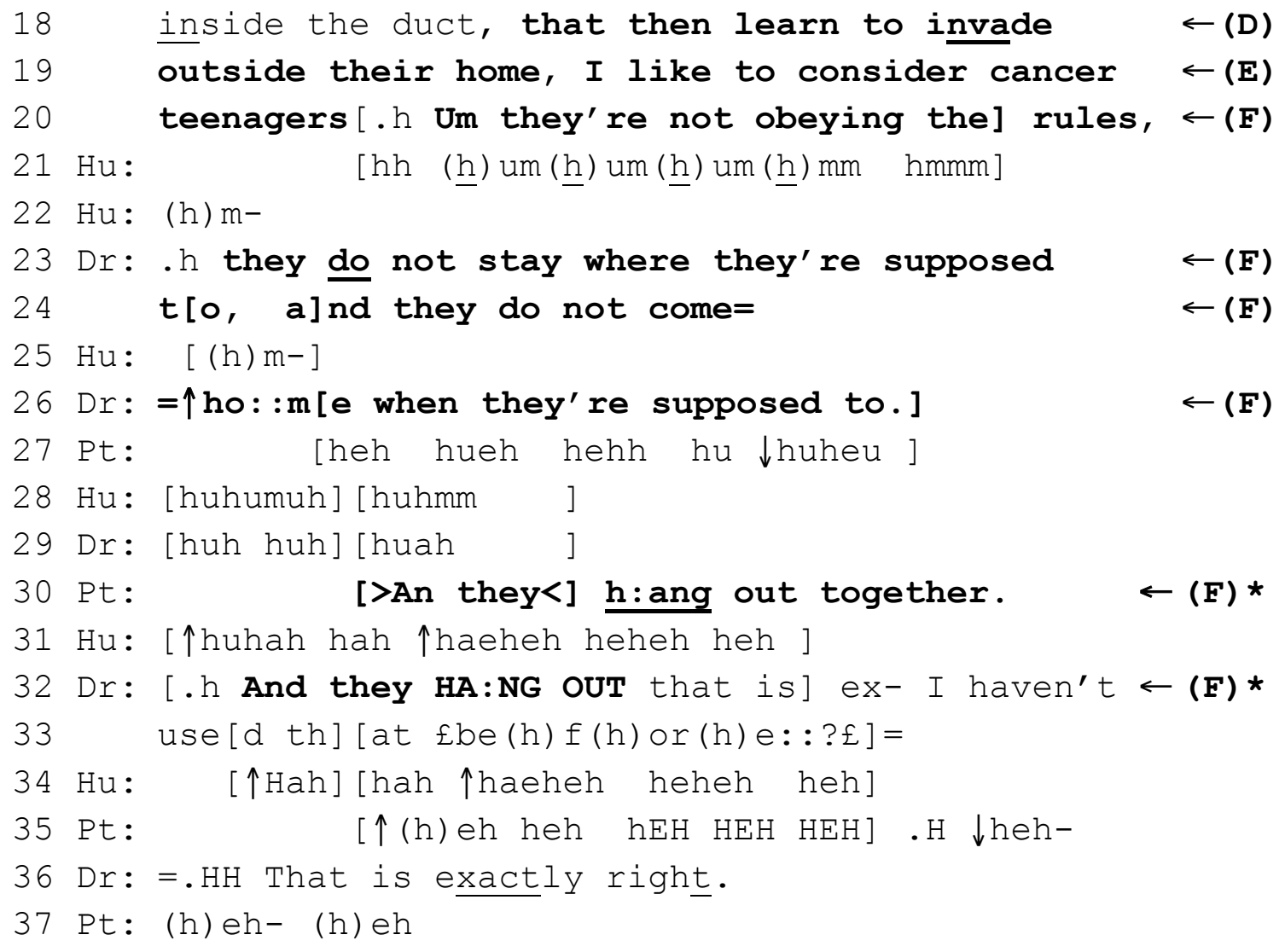

Note that at (D) the surgeon already attributes human characteristics (e.g., "learn" and "invade") to cancer. This formulation then acts as a launching pad for her analogy: "I like to consider cancer teenagers" (E), which elicits immediate laughter from the patient's husband. In overlap, the surgeon continues her turn (line 20) with the first part of a threepart list of transgressive teenager behaviors that substantiates her analogy, "they're not obeying the rules" (F). The patient's husband receipts this with a short laugh particle "(h)m-" (line 22), and the surgeon continues with the second and third items of her list-inprogress — they do not stay where they supposed to, or come home when they are supposed to (F). The surgeon's use of "they're", which hearably references teenagers, invites the patient and her husband to laugh about teenagers, not about "cancer" per se. 
The patient's husband produces a second laugh token at line 25 , precisely between the second and third items of the surgeon's list $(\mathrm{F})$, where it is clear that a list is underway and that the surgeon is using it in the service of procuring recipients' participation. And in line 25 the surgeon projects a completion point for her list by prefacing her third item with "and." The patient registers the surgeon's list as nearly complete (and treats it as humorous) by producing laughter in overlap with the latter half of her third list item (line 27). As noted, since lists regularly occur in three parts they serve as a sequential resource for recipients who can monitor third position items for possible completion (Jefferson 1990). After completing her list, the surgeon laughs in overlap with the patient's husband briefly before the patient actively collaborates with the surgeon by delivering a list item

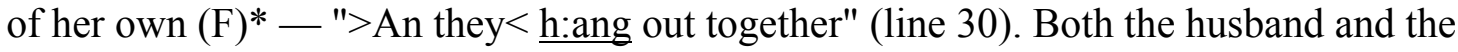
surgeon respond with laughter. The surgeon then repeats the patient's formulation ("and they hang out,") at (F)* in line 32, which is a way of confirming it. Interestingly, the surgeon's confirmation here repositions her as the "informer" and the one in a position to confirm or disconfirm the accuracy of a formulation, which she underscores in line 36 with an assessment — "That is exactly right." The participants achieve their institutional identities of "surgeon" and "patient" in and through the local production of actions such as these. That is, the surgeon's move to reposition herself as the "informer" (via her confirmation of the patient's contribution) works to recreate her identity as the surgeon, an expert on cancer.

Once again, the point to emphasize here is that listing is a valuable resource for speakers and hearers alike (Jefferson 1990). By constructing a list, the surgeon creates a slot for patients (and their families) to participate. This is particularly significant in this 
section of the consultation, where the surgeon's extended educational narrative might otherwise stifle patients' active participation.

The surgeon then produces another summative three-part list (Extract 3c, below). $(3 c):[1-1-1 \mathrm{~A}]$

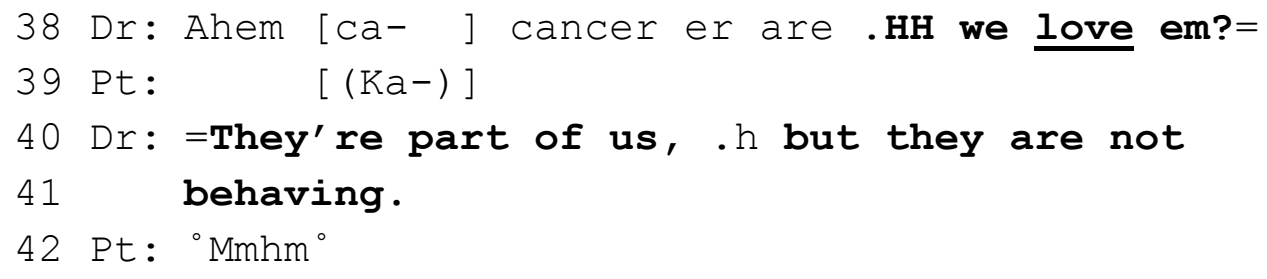

Here, the surgeon's list items are more general and have an "upshot" quality that works to summarize materials from (C)-(F). The patient's soft spoken " $\mathrm{Mmhm}^{\circ}$ (line 42) displays her alignment with the surgeon's formulation, and allows the surgeon to continue.

As she did in Case 1, the surgeon parlays materials from (E)-(F) of her narrative to inform the patient (and her husband) about a shortcoming of current cancer treatment $(\mathrm{G})$ :

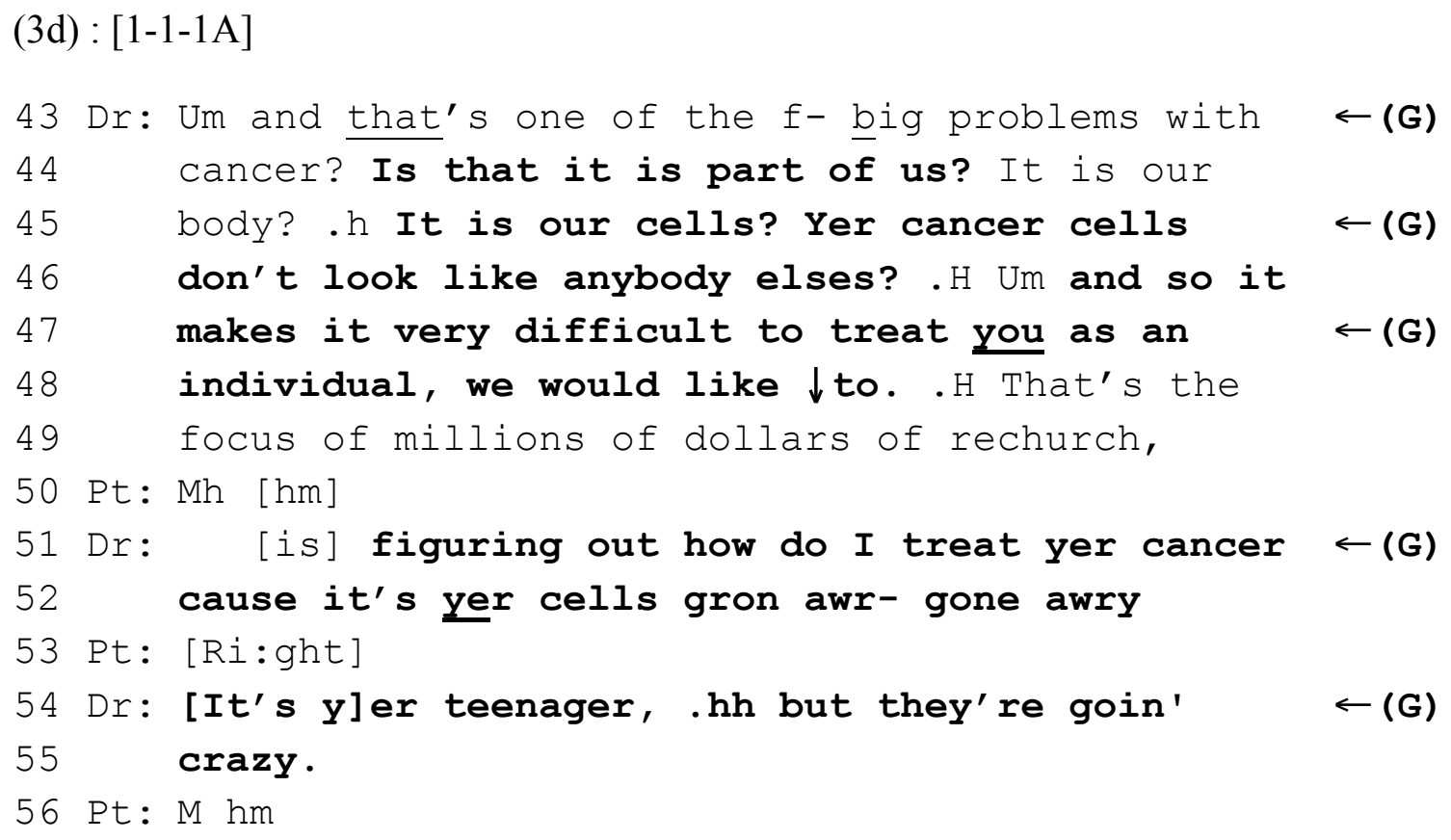


By comparing cancer to teenagers (E), then describing how cancer is like teenagers by listing some of the ornery behaviors that teenagers engage in and noting some of their attributes $(\mathrm{F})$, the surgeon relies on the patient and her husband to draw upon a commonsense understanding of teenagers to understand how cancer behaves. Moreover, she creates an interactional environment stocked with material that she can draw upon to explain that the ideal treatment for cancer (individualized treatment) is not possible (G) — medical science simply is not advanced enough yet. Although the surgeon knows that everyone's cancer is unique, technology has not yet advanced to the point where she can provide patients with truly individualized treatment. So here the surgeon is potentially working to establish some realistic expectations for treatment by contrasting ideal treatment with what is currently available. The figurative comparison (E) is what allowed the recipients to understand what the ideal treatment would be - it would treat their teenager and no one else's. Moreover, the surgeon emphasizes her desire to treat the patient as an individual - thus underscoring that she knows how to, and wants to, do right by the patient, but that this is being thwarted by circumstances beyond her control, both the current state of medical technology and the cancer itself.

\section{Case 4}

The patient in Case 4 has invasive ductal cancer. She has arrived at the consultation with her daughter. The following extract begins just after the surgeon has presented findings from the patient's mammograms:

(Extract 4) : [5-1-4A]

$\begin{array}{ll}1 & \text { Dr: Okay. .h That may be we do, just to make } \\ 2 & \text { shore:, nothing looks, (.) different after the } \\ 3 & \text { biopsy. .h Um an lemme explain why. Um so this } \\ 4 & \text { is the pathology report do you have a copy of }\end{array}$ 


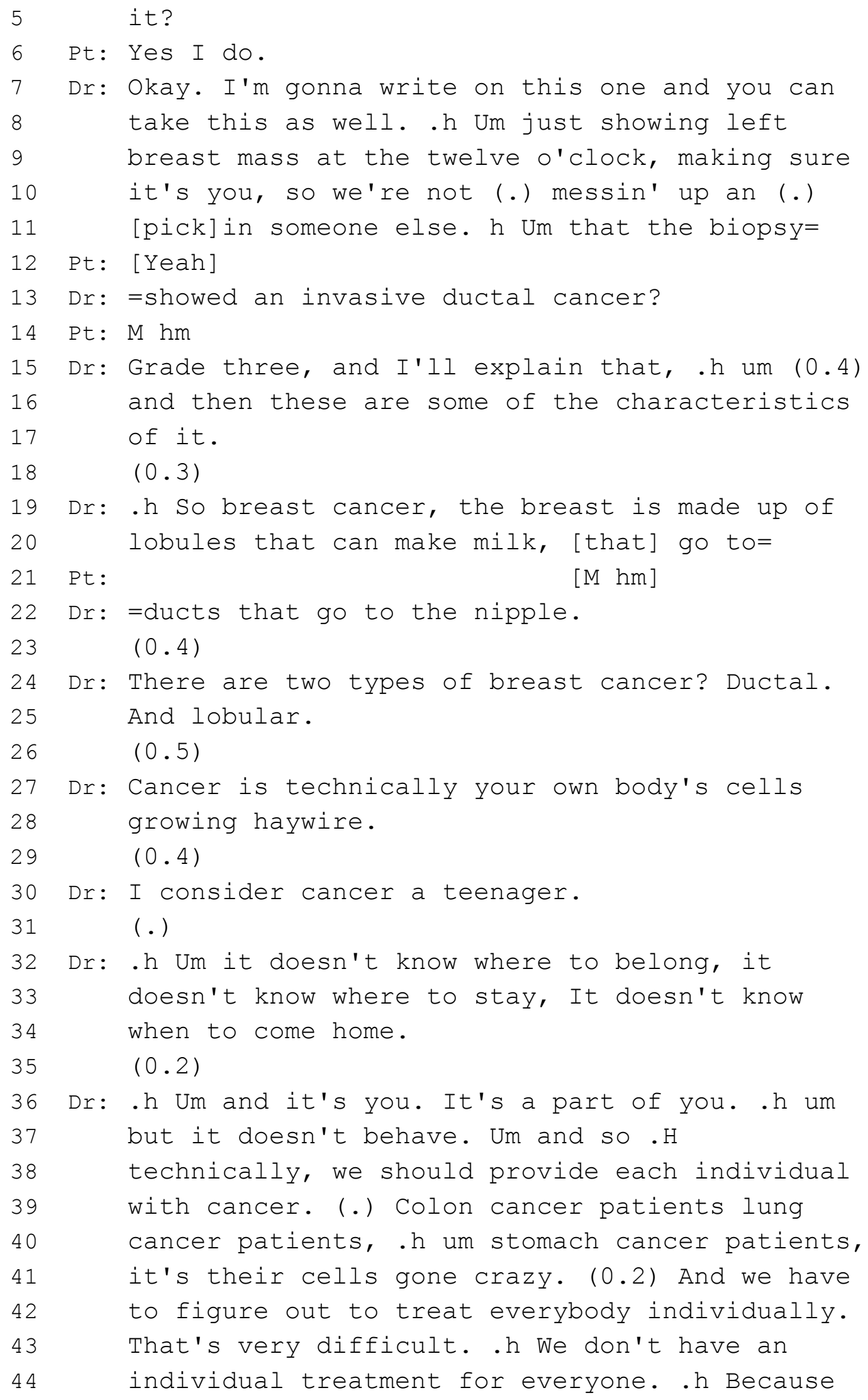


$\begin{array}{ll}45 & (.) \text { it's your body gone (.) awry. } \\ 46 & (0.3)\end{array}$

After orienting to the patient's pathology report (Extract 4, lines 3-5, above), and confirming that the patient has a copy of it, the surgeon uses it as a resource to organize this phase of the visit. She starts by reporting the biopsy location (lines 8-9), then reporting that she has checked that this biopsy report is in fact, the patient's (lines 9-11). ${ }^{4}$ At (A) below, the surgeon reports the patient's official diagnosis — ".h Um that the biopsy showed an invasive ductal cancer? Grade three." She then projects some of the items that she plans to explain by delivering a type of agenda-glossing utterance in lines $15-17$

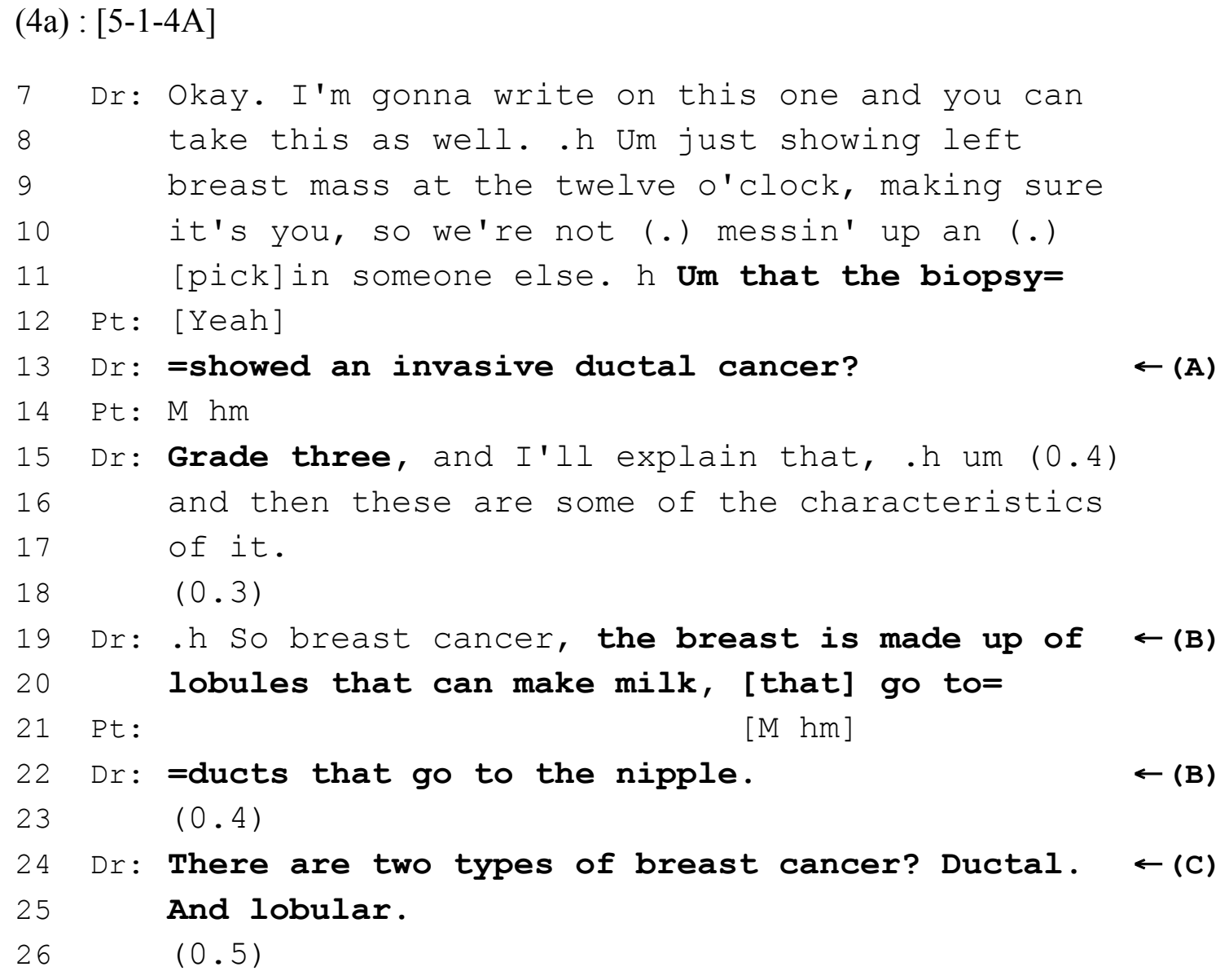


In line 19 the surgeon projects an explanation of breast cancer by prefacing her turn with "So breast cancer". At (B) the surgeon inserts a description of the anatomy of the breast, which, by virtue of its positioning, is hearable as part of a larger description of breast cancer. Having described the anatomy of the breast (lobules, ducts, nipple), the surgeon can use these components in (C) wherein she reports that there are two types of breast cancer - ductal and lobular.

At (D), below, the surgeon describes what cancer is: "technically your own body's cells growing haywire." Then she offers the analogy, "I like to consider cancer a teenager" (E).

(4b) : [5-1-4A]

27 Dr: Cancer is technically your own body's cells $\leftarrow$ (D)

28 growing haywire.

$29 \quad(0.4)$

30 Dr: I consider cancer a teenager.

31 (.)

32 Dr: .h Um it doesn't know where to belong, it $\leftarrow$ (F)

33 doesn't know where to stay, It doesn't know

34 when to come home.

$35 \quad(0.2)$

36 Dr: .h Um and it's you. It's a part of you. .h um $\leftarrow(F)$

37 but it doesn't behave. Um and so.H

38 technically, we should provide each individual

39 with cancer. (.) Colon cancer patients lung

40 cancer patients, .h um stomach cancer patients,

41 it's their cells gone crazy. (0.2) And we have

42 to figure out to treat everybody individually.

43 That's very difficult. .h We don't have an

44 individual treatment for everyone. .h Because $\leftarrow(G)$

45 (.) it's your body gone (.) awry.

$46 \quad(0.3)$ 
In this case however, neither the patient nor her daughter laugh, either here or after any component in her substantiation (lines 32-34). However, the surgeon constructs both the analogy and its substantiation in a different way than in Cases 1-3. First, the surgeon's analogy does not compare cancer to "teenagers" (plural) as it did in Cases 1-3, it compares cancer to "a teenager" (singular). Moreover, at (F) the surgeon mirrors this construction: she uses the referent "it" as she describes how cancer is like a teenager rather than the referent "they" as she did in Cases 1-3. Although both "cancer" and "a teenager" can be treated as singular, the referent "it" clearly refers to cancer. When speakers reference one teenager they do not generally use the referent "it." Rather, speakers use "he," "she," or even "they." As a result, the list is no longer hearable as a set of mischievous behaviors that teenagers engage in; rather, it is hearable as a description of how cancer behaves. Consequently, it is not "laughable."

In addition, in Cases 1-3 familiar teenager behaviors are enumerated, which are, in themselves, "laughable" from an adult standpoint. Therefore, even though the surgeon is comparing cancer to teenagers in all four cases, in Case 4 her use of "it" means she cannot draw upon the known-in-common foibles of teenagers to elicit an affiliative display from the recipients. This discrepancy may also be related to a shift in the list items themselves. Whereas in the previous three cases the surgeon's list items implicitly treated the referent (teenagers) as mischievous by stating that they do not do what they are "supposed to," in this case the list items implicitly treat the referent (cancer) as though it simply "doesn't know." So, if cancer on its own is not funny, then treating cancer as though it doesn't know any better certainly is not funny. Teenagers who do know better, 
but "don't behave," on the other hand, are funny, or are at the very least more "laughable."

Additionally, in terms of structure, the surgeon's list is different in Case 4 than it was in Cases 1-3. In Case 4 the surgeon does not preface her final list item with "and" as she does in Cases 1-3. This is a significant difference because, as noted in Cases 1-3, the utterance "and" projects list completion. Therefore, since the surgeon does not preface her final list item with "and" in Case 4, the patient and her daughter cannot use it as a resource to anticipate when speaker transition will be relevant. In other words, part of the reason the surgeon's list does not elicit a response from the patient and her daughter could be attributed to its weakly projected completion point.

Nevertheless, the analogy can still serve another function. As in Cases 1 and 3, the surgeon mobilizes materials from (F) to forge some realistic, tempered expectations for treatment by contrasting ideal treatment (lines 37-42) with the current state of medical knowledge (G). Individualized treatment would be ideal, but it is not possible. However, by contrasting ideal treatment with available treatment, the surgeon displays her desire to provide the best treatment possible. 


\section{CHAPTER V \\ DISCUSSION}

\section{Conclusions and Implications}

During pre-surgical consultations for breast cancer, surgeons use extended narratives to educate patients and their families about the disease. My analysis shows how one surgeon uses an analogy ("cancer is like teenagers") to educate patients and their families about the nature of breast cancer. However, I found that the surgeon uses her analogy to do additional work as well.

My analysis reveals that the surgeon's analogy regularly elicits laughter from recipients, which creates the appearance of rapport. Teenagers, "as everyone knows," are mischievous, while cancer, "as everyone knows," is scary; so when the surgeon juxtaposes these two blatantly incongruous categories she creates a mismatch that elicits laughter — with the exception of Case 4, where she uses the referent "it" instead of the referent "they," which makes her list hearable as simply describing how cancer behaves rather than as how teenagers behave. Moreover, when the surgeon substantiates her analogy, she uses a list to outline teenage behaviors from the perspective of an "adult who knows better," describing (in a reproving manner) the specific ways that teenagers break the rules. In so doing, she effectively asks the patient (and her family) to see these familiar characteristics in cancer, an entity that is commonly known to be reviled and feared. The surgeon's positioning of the list directly after her analogy makes it possible 
for her to talk about cancer by talking about teenagers, thereby creating an interactional environment that is more hospitable to talk concerning the nature of the disease. That is, one way to talk about invasive cancer, it seems, is to talk about it indirectly, by comparing it to something that is familiar to all adults.

Additionally, the surgeon's analogy + substantiation in Cases 1-3 promotes affiliative patient participation at a particular location in the consultation, where the surgeon's extended educational narrative would otherwise provide very few places for patients and their families to become actively involved. She facilitates this participation by using a list format to enumerate the mischievous behaviors of teenagers. The recognizability of lists make them valuable resources for recipients, who can use their familiar three-part structure to anticipate when speaker transition (i.e., participation) will become relevant.

In addition, the surgeon's list items include common teenager behaviors and attributes, which she can then mobilize to facilitate subsequent components of her educational narrative. For example, in Case 1 the surgeon draws upon the behaviors she listed to explain the difference between non-invasive cancer and the patient's invasive cancer: Unlike non-invasive cancer cells, this patient's ductal cells have "learned" how to get outside of their "home," they are not where they are "supposed to be," and now they have "figured out" how to get to the patient's lymph nodes. The surgeon also mobilizes her analogy to show patients that, ideally, treatment for breast cancer would be individualized (it would treat their "teenager" and no one else's), but individualized treatment is not yet possible - medical science simply is not advanced enough. By comparing ideal treatment with available treatment the surgeon may be working to forge 
some realistic, tempered expectations for treatment. At the same time, the surgeon emphasizes her desire to treat each patient as an individual — thus underscoring that she knows how to, and wants to, do right by the patient, but that this is being thwarted by circumstances beyond her control, both the current state of medical technology and the cancer itself. In this way, the surgeon orients to providing what some scholars have called "patient-centered care" (Mead and Bower 2000). Future research on patient-centered care would benefit from a detailed understanding of how doctors create the appearance of patient-centeredness in doctor-patient interaction.

It is important to consider the implications these types of educational procedures may have for understanding what "informed consent" means and how it is achieved during preoperative surgical consultations. While my analysis does not attempt to elucidate informed consent specifically, it is in and through these types of educational sequences that surgeons are expected to ensure that patients are informed about their breast cancer and how it can be treated. The understandings that emerge are interactional accomplishments. It is likely that current versions of what counts as informed consent are idealized versions, meaning they are not necessarily based on a detailed understanding of what actually happens during surgical consultations.

My work has demonstrated that there is more to medical analogies than symbolism and cognition — there is social action. Prior research has focused on why people use figurative language, how it reflects cognitive processes and cultural values and beliefs, and in what ways it comes to bear on the illness experience. As a result, much of the prior research on figurative expressions in illness contexts has neglected how people actually use them in real-time conversation. What I hoped to have demonstrated 
here is that people use figurative comparisons in strategic, orderly ways to get things done in and through talk-in-interaction.

\section{Limitations}

One potential limitation of my study is the lack of video recorded data. Since I was not able to see what the participants could see during the consultations, I did not have direct access to the non-vocal resources that they had access to (e.g., eye gaze, gestures, facial expressions etc.). However, while it is true that participants in these data may have used any number of non-vocal resources, it is also true that many (if not most) of their actions were made recognizable through talk. Another potential limitation is my small sample size; in the future I would like to gain access to more examples of this phenomenon, to study similarities and differences between them (as between cases 1-3 and Case 4 in this data set) and achieve a better understanding of how it works. 


\section{REFERENCES}

American Cancer Society. 2015. Cancer Facts \& Figures. Atlanta, GA: American Cancer Society.

Atkinson, J. Maxwell. 1985. "Refusing Invited Applause: Preliminary Observations from a Case Study of Charismatic Oratory." In The Handbook of Discourse Analysis, edited by T.A. van Dijk. London: Academic Press Vol. III:161-81.

Barry, Colleen, Victoria Bresscall, Kelly D. Brownell, and Mark Schlesinger. 2009. "Obesity Metaphors: How Beliefs about Obesity Affect Support for Public Policy." The Milbank Quarterly 87(1):7-47.

Blumer, Herbert. 1969. Symbolic Interactionism: Perspective and Method. Englewood Cliffs, NJ: Prentice-Hall.

Cameron, Lynne. 1999. Identifying and Describing Metaphor in Spoken Discourse Data." Pp. 105-132 in Researching and Applying Metaphor, edited by L. Cameron and G. Low. Cambridge: Cambridge University Press.

Cameron, Lynne, and Alice Deignan. 2003. "Using Large and Small Corpora to Investigate Tuning Devices Around Metaphor in Spoken Discourse." Metaphor and Symbol 18(3):149-160.

Cameron, Lynne, and Juurd H. Stelma. 2004. "Metaphor Clusters in Discourse." Journal of Applied Linguistics 1(2):107-136.

Cameron, Lynne. 2007. "Confrontation or Complementarity? Metaphor in Language use and Cognitive Metaphor Theory." Annual Review of Cognitive Linguistics 5(1):107-135.

Cameron, Lynne. 2008. "Metaphor and Talk." Pp. 197-211 in The Cambridge Handbook of Metaphor and Thought, edited by R.W. Gibbs. Cambridge: Cambridge University Press.

Carle Cancer Center. 2014. "Treatment Options." Urbana, IL: Carle Cancer Center. Retrieved July 28, 2014. (http://www.carle.org/MedicalServices/Cancer/ Services.aspx\#surgery) 
Casarett, David, Amy Pickard, Jessica M. Fishman, Stewart C. Alexander, Robert M. Arnold, Kathryn I. Pollak, and James A. Tulsky. 2010. "Can Metaphors and Analogies Improve Communication with Seriously Ill Patients?" Journal of Palliative Medicine 13(3):255-260.

Charmaz, Kathy. 1991. Good Days, Bad Days: The Self in Chronic Illness and Time. New Brunswick, NJ: Rutgers University Press.

Clayman, Steve and Virginia Teas Gill. 2012. "Conversation Analysis." Pp.120-134 in Gee and Handford (Eds.) The Routledge Handbook of Discourse Analysis. London: Routledge.

Clow, Barbara. 2001. "Who's Afraid of Susan Sontag? or, the Myths and Metaphors of Cancer Reconsidered." Social History of Medicine 14(2):293-312.

Conrad, Peter and Kristin Barker. 2010. "The Social Construction of Illness: Key Insights and Policy Implications." Journal of Health and Social Behavior 51(S):S67-S79.

Coulehan, Jack. 2003. "Metaphor and Medicine: Narrative in Clinical Practice." Yale Journal of Biology and Medicine 76(1):87-95.

Drew, Paul and Elizabeth Holt. 1988. "Complainable Matters: The Use of Idiomatic Expressions in Making Complaints." Social Problems 35(4):398-417. 1995. "Idiomatic Expressions and their Role in the Organisation of Topic Transition in Conversation." Pp. 117-132 in Idioms: Structural and Psychological Perspectives, edited by M. Everaert, E.-J. v. d. Linden, A. Schenk, and R. Schreuder. Hillsdale, NJ: Lawrence Erlbaum Associates.

- 1998. "Figures of Speech: Figurative Expressions and the Management of Topic Transition in Conversation." Language in Society 27(1):495-522.

Eisenberg, Leon. 1977. "Disease and Illness: Distinctions Between Professional and Popular Ideas of Sickness." Culture, Medicine and Psychiatry 1(1):9-23.

Freidson, Eliot. 1970. Profession of Medicine: A Study of the Sociology of Applied Knowledge. New York: Harper and Row.

Fuks, Aberham. 2010. "The Military Metaphors of Modern Medicine." Pp. 57-68 in The Meaning Management Challenge: Making Sense of Health, Illness and Disease, edited by Z. Li and T. L. Long. Oxford, UK: Inter-Disciplinary Press.

Garfinkel, Harold. 1964. "Studies of the Routine Grounds of Everyday Activities." Social Problems 11(3):225-250.

. 1967. Studies in Ethnomethodology. Englewood Cliffs, NJ: Prentice-Hall. 
Gill, Virginia, Teas. 2005. "Patient 'Demand' for Medical Interventions: Exerting Pressure for an Offer in a Primary Care Clinic Visit." Research on Language and Social Interaction 38(4):451-79.

2014. "'I Absolutely Positively Want Both of Them Off': Conflicts About Treatment in Surgical Consultations for Early-Stage Breast Cancer." Presented June 27th, 2014 at the 4th International Conference on Conversation Analysis, University of California, Los Angeles.

Gill, Virginia, Teas, Anita Pomerantz, and Paul Denvir. 2010. "Pre-Emptive Resistance: Patients' Participation in Diagnostic Sense-Making Activities." Sociology of Health \& Illness 32(1):1-20.

Glaser, Barney, G. and Anselm C. Strauss. 1965. Awareness of Dying. Chicago, IL: Aldine Transaction.

Harrow, Alison, Mary Wells, Gerry Humphris, Cara Taylor, and Brian Williams. 2008. "'Seeing is believing, and believing is seeing': An exploration of the meaning and impact of women's mental images of their breast cancer and their potential origins." Patient Education and Counseling 73(1):339-346.

Heritage, John. [1984] 1986. Garfinkel and Ethnomethodology. Cambridge, MA: Blackwell Publishers Inc. . 1984. "A Change of State Token and Aspects of Its Sequential Placement." Pp.299-345 in Structures of Social Action, edited by M. J. Atkinson and J. Heritage. Cambridge: Cambridge University Press.

2013. "Asymmetries of Knowledge in Patient-Provider Encounters: Three Studies Adopting Conversation Analysis." Patient Education and Counseling 92(1):1-2.

Heritage, John, and Steven Clayman. 2010. Talk in Action: Interactions, Identities, and Institutions. Malden, MA: Wiley-Blackwell.

Holt, Elizabeth, and Paul Drew. 2005. "Figurative Pivots: The Use of Figurative Expressions in Pivotal Topic Transition." Research on Language and Social Interaction. 38(1):35-61.

Jefferson, Gail. 1974. "Error Correction as an Interactional Resource." Language in Society 2(1):181-199.

Jefferson, Gail. 1990. "List Construction as a Task and Resource." Pp. 63-92 in Interactional Competence, edited by G. Psathas. Lanham, MD: University Press of America. 
Lakoff, George and Mark Johnson. 1980. Metaphors we Live by. Chicago, IL: The University of Chicago Press.

Mead, Nicola, and Peter Bower. 2000. "Patient-Centredness: A Conceptual Framework and Review of the Empirical Literature." Social Science and Medicine 51(7):1087-1110.

Niebert, Kai, Sabine Marsch, and David F. Treagust. 2012. "Understanding needs embodiment: A theory-guided reanalysis of the role of metaphors and analogies in understanding science." Science Education 96(5):849-877.

Parsons, Talcott. 1951. The Social System. London: The Free Press of Glencoe.

Pomerantz, Anita, and B.J. Fehr. 1997. "Conversation Analysis: An Approach to the Study of Social Action as Sense Making Practices." Pp.64-91 in Discourse as Social Interaction, edited by T. A. Dijk. London: Sage Publications.

Rawls, Warfield, Anne. 1985. "Reply to Gallant and Kleinman on Symbolic Interactionism vs. Ethnomethodology." Symbolic Interaction 8(1):121-140.

Reisfield, Gary, M., and George R. Wilson. 2004. "Use of Metaphor in the Discourse on Cancer." Journal of Clinical Oncology 22(19):4024-27.

Sacks, Harvey, Emanuel A. Schegloff, and Gail Jefferson. 1974. "A Simplest Systematics for the Organization of Turn-Taking for Conversation." Language 50(4):696-735.

Sacks, Harvey. 1984. "Notes on Methodology." Pp. 21-7 edited by Gail Jefferson from various lectures, in Structures of Social Action edited by J. M. Atkinson and J. Heritage. Cambridge: Cambridge University Press.

—. [1992] 1995. Lectures on Conversation Volumes I \& II, edited by Gail Jefferson. Malden, MA: Blackwell Publishing.

Schegloff, Emanuel, A., and Harvey Sacks. 1973. “Opening Up Closings.” Semiotica. 8:289-327.

Schegloff, Emanuel A. [2007] 2010. Sequence Organization in Interaction: A Primer in Conversation Analysis. Cambridge, UK: Cambridge University Press.

Scherer, Aaron, M., Laura D. Scherer, and Angela Fagerlin. 2015. "Getting Ahead of Illness: Using Metaphors to Influence Medical Decision Making." Medical Decision Making 35(1):37-45.

Schiappa, Edward. 2003. Defining Reality: Definitions and the Politics of Meaning. Carbondale, IL: Southern Illinois University Press. 
Schutz, Alfred. 1967. "Phenomenology and the Social Sciences." Pp. 118-39 in Collected Papers, Vol. 1, The Problem of Social Reality, edited by M. Natanson. The Hague, The Netherlands: M. Nijhoff.

Semino, Elena, John Heywood, and Mick Short. 2004. "Methodological Problems in the Analysis of Metaphors in a Corpus of Conversations about Cancer." Journal of Pragmatics 36(1):1271-1294.

Skelton, John, R., Andy M. Wearn, and F. D. Richard Hobbs. 2002. "A ConcordanceBased Study of Metaphoric Expressions Used by General Practitioners and Patients in Consultation." British Journal of General Practice 52(1):114-118.

Sontag, Susan. 1978. Illness as Metaphor. New York: Farrar, Straus and Giroux.

ten Have, Paul. 1999. Doing Conversation Analysis: A Practical Guide. London: Sage.

Whaley, Bryan, Anne Stone, Sheila Brady, and Reid Whaley. 2014. "Explaining Diabetes: Studying the Effects of Using Analogies to Talk About Illness." Journal of Diabetes Nursing 18(2):72-7 


\section{APPENDIX A \\ TRANSCRIPTION NOTATION}

\section{Adapted from Jefferson (1974)}

[ ] Square brackets show beginning and ending of overlap in speakers' utterances.

(0.5) Numbers in parentheses are silences timed to tenths of a second.

(.) Period in parentheses is a very brief silence (less than one-tenth of a second).

((horn honks)) Transcriber's comments are enclosed in double parentheses.

( ) Empty parentheses denote indecipherable utterance.

(text) Text in parentheses is transcriber's "best guess" as to a speaker's utterance.

Period indicates downward intonation, not necessarily the end of a sentence.

? Question mark indicates upward intonation, not necessarily a question.

: Colon(s) indicate that a sound is stretched. The more colons, the longer the sound.

, Commas indicate "continuing" intonation.

.hh "h"s with preceding period indicate audible in-breath; the more " $h " s$, the longer the inbreath.

hh "h"s with no preceding period indicate audible out-breath; the more " $h$ "s, the longer the out-breath

WORD Upper case indicates especially loud sounds relative to the surrounding talk.

every Underlines indicate parts of words that are stressed.

n- $\quad$ Dash indicates a cutoff of a sound.

(h) Parenthesized " $\mathrm{h}$ " indicates plosiveness, often associated with laughter, crying, breathlessness, etc.

$>$ word $<\quad$ Words inside carets are spoken more quickly than surrounding talk.

${ }^{\circ}$ word ${ }^{\circ} \quad$ Words inside degree signs are spoken more quietly than surrounding talk.

$\uparrow \downarrow \quad$ An upward-pointing arrow indicates a high-pitched sound; a downward arrow indicates a low-pitched sound.

$=\quad$ Equal signs means utterances are latched. 


\section{ENDNOTES}

${ }^{1}$ These studies have encountered methodological problems that involve issues such as: determining the exact boundaries between metaphorical and literal expressions in given contexts, accurately identifying the source and target domains related to given linguistic expressions, and converting collections of individual linguistic metaphors into generalizable conceptual metaphors, just to name a few (see Semino, Heywood, and Short 2004).

${ }^{2}$ The researcher (Dr. Gill) was not present in the consultation room when the recordings were made, but participants did occasionally orient to the presence of the recording device in passing; however, these instances usually occurred at the very beginning of the visit before participants got down to the "business" of the consultation (i.e., the reason for the visit). Here, as documented elsewhere, "hyper-consciousness about the recording machine tends to be short-lived, receding into the background as the participants become enmeshed in the practical concerns of their daily lives" (Clayman and Gill 2012:121).

${ }^{3}$ At the onset of the consultation (not shown here) the surgeon inquires about the patient's initial consultation with a surgeon located elsewhere in the U.S. The surgeon then orients to this patient as reasonably more informed than the average patient (e.g., "okay. (1.7) And um I usually kind of go through a whole shpeal about breast cancer? And I'm happy to do some of that? But you have a little bit of a fund of knowledge?" to which the patient responds with a confirmation token "Right" and the surgeon continues with "And so I don't feel like we have to go: (0.4) through the entire thing?").

${ }^{4}$ As was observed in Case 1, the surgeon's utterance, "making sure it's you, so we're not (.) messin' up an (.) [pick]in someone else." in lines 9-11 may be a way of displaying her orientation to a common patient concern - medical mix-ups. 